\title{
Screening of ח-Basic Naphthalene and Anthracene Amplifiers for m-Acidic Synthetic Pore Sensors
}

\author{
Shinya Hagihara, Ludovic Gremaud, Guillaume Bollot, Jiri Mareda and Stefan Matile* \\ Department of Organic Chemistry, University of Geneva, Geneva, Switzerland \\ stefan.matile@chiorg.unige.ch
}

\section{Supporting Information}

General. As in ref (S1) with minor modifications: Reagents for synthesis were purchased from Fluka or Aldrich, egg yolk phosphatidylcholine (EYPC) from Avanti polar lipids, HATU from Applied Biosystems, buffers, and salts from Sigma or Fluka-Aldrich. Column chromatography was carried out on silica gel 60 (Fluka, 40-63 m). Analytical (TLC) and preparative thin layer chromatography (PTLC) were performed in silica gel 60 (Fluka, 0.2 $\mathrm{mm}$ ) and silica gel GF (Analtech, $1000 \mu \mathrm{m}$ ), respectively. Purity of the product was verified by using either Jasco HPLC system (PU-980, UV-970, FP-920) or Agilent 1100 Series. Melting points ( $\mathrm{mp}$ ) was recorded on a heating table from Reichert (Austria). IR spectra were recorded on a Perkin Elmer Spectrum One FT-IR spectrometer (ATR, Golden Gate, unless stated) and are reported in $\mathrm{cm}^{-1}$ with band intensities indicated as s (strong), $\mathrm{m}$ (medium), w (weak). ESI-MS and APCI-MS were performed on a Finnigan MAT SSQ 7000 instrument. ${ }^{1} \mathrm{H}$ and ${ }^{13} \mathrm{C}$ spectra were recorded (as indicated) on a Bruker $400 \mathrm{MHz}$ spectrometer and are reported as chemical shifts $(\delta)$ in ppm relative to solvent peak. Spin multiplicities are reported as a singlet $(\mathrm{s})$, doublet $(\mathrm{d})$, triplet $(\mathrm{t})$, with coupling constants $(J)$ given in $\mathrm{Hz}$, or multiplet (m). ${ }^{1} \mathrm{H}$ and ${ }^{13} \mathrm{C}$ resonances were assigned with the aid of additional information from $2 \mathrm{D}$ NMR spectra [H,H-COSY, DEPT135, HSQC, HMQC and HMBC]. UV-Vis spectra were measured on a Varian Cary 1 Biospectrophotometer. Fluorescence measurements were preformed on a FluoroMax-2, Jobin Yvon-Spex. The Mini-Extruder with a polycarbonate membrane, pore size $100 \mathrm{~nm}$, used for LUV preparation was from Avanti polar lipids. Cyclic voltammetry was measured on $\mathrm{CHI} 600 \mathrm{C}$ electrochemical analyzer.

Abbreviations. CF, 5(6)-carboxyfluorescein; DAA: Dialkoxyanthracene; DAN: Dialkoxynaphthalene; EYPC-LUVs: Egg yolk phosphatidylcholine large unilamellar vesicles; NDI: Naphthalenediimide. 
<smiles>Oc1ccc2ccccc2c1O</smiles>

24<smiles>CCCCCOC(=O)COc1ccccc1O</smiles>
25<smiles>CCCCCOc1ccccc1OCC(=O)OCC(=O)OCCCC</smiles><smiles>COC(=O)COc1ccccc1OCC(=O)O</smiles>

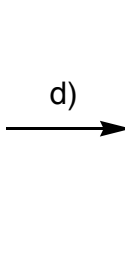<smiles>NNC(=O)COc1cccc2cc(OCC(=O)O)ccc12</smiles>

Scheme S1. a) $t$-Butyl bromoacetate, $\mathrm{K}_{2} \mathrm{CO}_{3}$, acetone; b) methyl bromoacetate, $\mathrm{K}_{2} \mathrm{CO}_{3}$, acetone; c) TFA, $\mathrm{CH}_{2} \mathrm{Cl}_{2}$; d) $\mathrm{H}_{2} \mathrm{NNH}_{2} \bullet \mathrm{H}_{2} \mathrm{O}, \mathrm{MeOH}$.

Isomers 25 (see Table 1 for isomers). A solution of an individual isomer 24 (2.0 g, 12.5 $\mathrm{mmol})$, potassium carbonate $(2.4 \mathrm{~g}, 17.4 \mathrm{mmol})$ and $t$-butyl bromoacetate $(2.6 \mathrm{ml}, 17.3 \mathrm{mmol})$ in acetone $(20 \mathrm{ml})$ was heated to $70{ }^{\circ} \mathrm{C}$ and stirred overnight. After cooling, the mixture was poured into $1 \mathrm{~N} \mathrm{HCl}(50 \mathrm{ml})$, extracted with EtOAc, washed with water (2 times) and brine, dried with anhydrous $\mathrm{Na}_{2} \mathrm{SO}_{4}$, filtered and concentrated. Purification of the crude product by column chromatography $\left(\mathrm{CH}_{2} \mathrm{Cl}_{2}\right)$ yielded the corresponding individual isomer 25 as a colorless solid. IR (neat): 3369 (m), $2984(\mathrm{w}), 1720$ (s), $1598(\mathrm{~m}), 1521(\mathrm{~m}), 1415$ (s), 1366 (s), 1243 (s), 1228 (s), 1145 (s), 1095 (s), 910 (m), 838 (m), 759 (s); ESI MS (MeOH/CH $\mathrm{Cl}_{2}$ 1:1): $293\left(100,\left[\mathrm{M}+\mathrm{NH}_{4}\right]^{+}\right), 275\left(16,[\mathrm{M}+\mathrm{H}]^{+}\right), 219\left(73,[\mathrm{M}-t-\mathrm{Bu}+\mathrm{H}]^{+}\right), 173(57,[\mathrm{M}-t-$ $\left.\left.\mathrm{Bu}-\mathrm{CO}_{2}+\mathrm{H}\right]^{+}\right)$.

2,7-Isomer. Yield: $16 \%$; ${ }^{1} \mathrm{H}$ NMR $\left(400 \mathrm{MHz}, \mathrm{CDCl}_{3}\right): 7.68\left(\mathrm{~d},{ }^{3} \mathrm{~J}(\mathrm{H}, \mathrm{H})=8.8 \mathrm{~Hz}, 1 \mathrm{H}\right), 7.67$ $\left(\mathrm{d},{ }^{3} J(\mathrm{H}, \mathrm{H})=8.8 \mathrm{~Hz}, 1 \mathrm{H}\right), 7.07\left(\mathrm{dd},{ }^{3} J(\mathrm{H}, \mathrm{H})=8.8 \mathrm{~Hz},{ }^{3} J(\mathrm{H}, \mathrm{H})=2.4 \mathrm{~Hz}, 1 \mathrm{H}\right), 7.03\left(\mathrm{~d},{ }^{3} J\right.$ $(\mathrm{H}, \mathrm{H})=2.4 \mathrm{~Hz}, 1 \mathrm{H}), 6.96\left(\mathrm{dd},{ }^{3} J(\mathrm{H}, \mathrm{H})=8.8 \mathrm{~Hz},{ }^{3} J(\mathrm{H}, \mathrm{H})=2.4 \mathrm{~Hz}, 1 \mathrm{H}\right), 6.91\left(\mathrm{~d},{ }^{3} J(\mathrm{H}, \mathrm{H})=\right.$ $2.4 \mathrm{~Hz}, 1 \mathrm{H}), 4.62(\mathrm{~s}, 2 \mathrm{H}), 1.51(\mathrm{~s}, 9 \mathrm{H}) ;{ }^{13} \mathrm{C} \mathrm{NMR}\left(100 \mathrm{MHz}, \mathrm{CDCl}_{3}\right): 168.3$ (s), 156.7 (s), 154.3 (s), 135.9 (s), 129.8 (d), 129.7 (d), 124.9 (s), 116.4 (d), 115.8 (d), 109.1 (d), 106.1 (d), $82.7(\mathrm{~s}), 65.9(\mathrm{t}), 28.3(\mathrm{q})$.

7,1-Isomer. The 1,7-isomer (1-hydroxy, 7-t-butoxycarbonylmethoxy) and the 7,1-isomer (1$t$-butoxycarbonylmethoxy, 7-hydroxy) were separated by column chromatography $\left(\mathrm{CH}_{2} \mathrm{Cl}_{2}, R_{\mathrm{f}}\right.$ $\left.(7,1)=0.14, R_{\mathrm{f}}(1,7)=0.16\right)$. Yield: $22 \% ;{ }^{1} \mathrm{H} \mathrm{NMR}\left(400 \mathrm{MHz}, \mathrm{CDCl}_{3}\right): 7.76\left(\mathrm{~d},{ }^{3} J(\mathrm{H}, \mathrm{H})=\right.$ $8.8 \mathrm{~Hz}, 1 \mathrm{H}), 7.71\left(\mathrm{~d},{ }^{3} J(\mathrm{H}, \mathrm{H})=2.4 \mathrm{~Hz}, 1 \mathrm{H}\right), 7.45\left(\mathrm{~d},{ }^{3} J(\mathrm{H}, \mathrm{H})=8.0 \mathrm{~Hz}, 1 \mathrm{H}\right), 7.25\left(\mathrm{t},{ }^{3} J(\mathrm{H}, \mathrm{H})\right.$ $=8.0 \mathrm{~Hz}, 1 \mathrm{H}), 7.18\left(\mathrm{dd},{ }^{3} J(\mathrm{H}, \mathrm{H})=8.8 \mathrm{~Hz},{ }^{3} J(\mathrm{H}, \mathrm{H})=2.4 \mathrm{~Hz}, 1 \mathrm{H}\right), 6.73\left(\mathrm{~d},{ }^{3} J(\mathrm{H}, \mathrm{H})=8.0\right.$ $\mathrm{Hz}, 1 \mathrm{H}), 4.73$ (s, 2H), 1.57 (s, 9H); ${ }^{13} \mathrm{C} \mathrm{NMR}\left(100 \mathrm{MHz}, \mathrm{CDCl}_{3}\right): 168.6$ (s), 153.8 (s), 152.8 (s), 130.1 (s), 129.6 (d), 126.9 (s), 123.1 (d), 121.4 (d), 118.6 (d), 105.7 (d), 104.6 (d), 82.9 $(\mathrm{s}), 66.2(\mathrm{t}), 28.3(\mathrm{q})$.

2,3-Isomer. Yield: $16 \% ;{ }^{1} \mathrm{H}$ NMR $\left(400 \mathrm{MHz}, \mathrm{CDCl}_{3}\right): 7.67\left(\mathrm{t},{ }^{3} \mathrm{~J}(\mathrm{H}, \mathrm{H})=9.2 \mathrm{~Hz}, 1 \mathrm{H}\right), 7.37$ $\left(\mathrm{dd},{ }^{3} J(\mathrm{H}, \mathrm{H})=8.8 \mathrm{~Hz},{ }^{3} J(\mathrm{H}, \mathrm{H})=1.2 \mathrm{~Hz}, 1 \mathrm{H}\right), 7.30(\mathrm{~s}, 1 \mathrm{H}), 7.07\left(\mathrm{dd},{ }^{3} J(\mathrm{H}, \mathrm{H})=8.8 \mathrm{~Hz},{ }^{3} J\right.$ $(\mathrm{H}, \mathrm{H})=1.2 \mathrm{~Hz}, 1 \mathrm{H}), 7.15(\mathrm{~s}, 1 \mathrm{H}), 4.74(\mathrm{~s}, 2 \mathrm{H}), 1.56(\mathrm{~s}, 9 \mathrm{H}) ;{ }^{13} \mathrm{C}$ NMR $\left(100 \mathrm{MHz}, \mathrm{CDCl}_{3}\right)$ : 168.9 (s), 147.0 (s), 146.8 (s), 130.9 (s), 128.8 (s), 126.8 (d), 126.6 (d), 125.1 (d), 124.0 (d), $110.9(\mathrm{~d}), 110.1(\mathrm{~d}), 83.6(\mathrm{~s}), 68.0(\mathrm{t}), 28.3(\mathrm{q})$. 
1,4-Isomer. Yield: $10 \%$; ${ }^{1} \mathrm{H}$ NMR $\left(400 \mathrm{MHz}, \mathrm{CDCl}_{3}\right)$ : 8.32-8.28 (m, 1H), 8.11-8.07 (m, $1 \mathrm{H}), 7.52-7.48(\mathrm{~m}, 2 \mathrm{H}), 6.67\left(\mathrm{~d},{ }^{3} J(\mathrm{H}, \mathrm{H})=8.0 \mathrm{~Hz}, 1 \mathrm{H}\right), 6.54\left(\mathrm{~d},{ }^{3} J(\mathrm{H}, \mathrm{H})=8.0 \mathrm{~Hz}, 1 \mathrm{H}\right), 4.62$ (s, 2H), 1.48 (s, 9H); ${ }^{13} \mathrm{C} \mathrm{NMR} \mathrm{(100} \mathrm{MHz,} \mathrm{CDCl}_{3}$ ): 169.1 (s), 148.1 (s), 146.4 (s), 126.6 (s), 126.2 (d), 126.1 (d), 125.6 (s), 122.4 (d), 121.8 (d), 107.7 (d), 105.4 (d), 82.8 (s), 66.9 (t), $28.3(\mathrm{q})$.

1,7-Isomer. The 1,7-isomer (1-hydroxy, 7-t-butoxycarbonylmethoxy) and the 7,1-isomer (1$t$-butoxycarbonylmethoxy, 7-hydroxy) were separated by column chromatography $\left(\mathrm{CH}_{2} \mathrm{Cl}_{2}, R_{\mathrm{f}}\right.$ $\left.(7,1)=0.14, R_{\mathrm{f}}(1,7)=0.16\right)$. Yield: $10 \% ;{ }^{1} \mathrm{H} \mathrm{NMR}\left(400 \mathrm{MHz}, \mathrm{CDCl}_{3}\right): 7.78\left(\mathrm{~d},{ }^{3} J(\mathrm{H}, \mathrm{H})=\right.$ $8.8 \mathrm{~Hz}, 1 \mathrm{H}), 7.48\left(\mathrm{~d},{ }^{3} J(\mathrm{H}, \mathrm{H})=2.8 \mathrm{~Hz}, 1 \mathrm{H}\right), 7.43\left(\mathrm{~d},{ }^{3} J(\mathrm{H}, \mathrm{H})=8.4 \mathrm{~Hz}, 1 \mathrm{H}\right), 7.30\left(\mathrm{dd},{ }^{3} J\right.$ $\left.(\mathrm{H}, \mathrm{H})=8.8 \mathrm{~Hz},{ }^{3} J(\mathrm{H}, \mathrm{H})=2.8 \mathrm{~Hz}, 1 \mathrm{H}\right), 7.27\left(\mathrm{dd},{ }^{3} J(\mathrm{H}, \mathrm{H})=8.0 \mathrm{~Hz},{ }^{3} J(\mathrm{H}, \mathrm{H})=7.6 \mathrm{~Hz}, 1 \mathrm{H}\right)$, $6.85\left(\mathrm{~d},{ }^{3} \mathrm{~J}(\mathrm{H}, \mathrm{H})=7.6 \mathrm{~Hz}, 1 \mathrm{H}\right), 4.68(\mathrm{~s}, 2 \mathrm{H}), 1.53(\mathrm{~s}, 9 \mathrm{H}) ;{ }^{13} \mathrm{C}$ NMR $\left(100 \mathrm{MHz}, \mathrm{CDCl}_{3}\right)$ : 168.5 (s), 155.7 (s), 150.8 (s), 130.9 (s), 129.7 (d), 125.2 (s), 124.0 (d), 120.5 (d), 119.5 (d), $109.3(\mathrm{~d}), 101.5(\mathrm{~d}), 82.8(\mathrm{~s}), 66.0(\mathrm{t}), 28.3(\mathrm{q})$.

1,3-Isomer. The 1,3-isomer (1-hydroxy, 3-t-butoxycarbonylmethoxy) and the 3,1-isomer (1$t$-butoxycarbonylmethoxy, 3-hydroxy) were separated by column chromatography $\left(\mathrm{CH}_{2} \mathrm{Cl}_{2}, R_{\mathrm{f}}\right.$ $\left.(1,3)=0.14, R_{\mathrm{f}}(3,1)=0.16\right)$. Yield: $5 \% ;{ }^{1} \mathrm{H}$ NMR $\left(400 \mathrm{MHz}, \mathrm{CDCl}_{3}\right): 8.07\left(\mathrm{~d},{ }^{3} J(\mathrm{H}, \mathrm{H})=\right.$ $8.0 \mathrm{~Hz}, 1 \mathrm{H}), 7.62\left(\mathrm{~d},{ }^{3} J(\mathrm{H}, \mathrm{H})=8.0 \mathrm{~Hz}, 1 \mathrm{H}\right), 7.41\left(\mathrm{dt},{ }^{3} J(\mathrm{H}, \mathrm{H})=8.0 \mathrm{~Hz},{ }^{3} J(\mathrm{H}, \mathrm{H})=2.0 \mathrm{~Hz}\right.$, $1 \mathrm{H}), 7.31\left(\mathrm{dt},{ }^{3} \mathrm{~J}(\mathrm{H}, \mathrm{H})=8.0 \mathrm{~Hz},{ }^{3} J(\mathrm{H}, \mathrm{H})=2.0 \mathrm{~Hz}, 1 \mathrm{H}\right), 6.68\left(\mathrm{~d},{ }^{3} J(\mathrm{H}, \mathrm{H})=2.0 \mathrm{~Hz}, 1 \mathrm{H}\right), 6.62$ $\left(\mathrm{d},{ }^{3} \mathrm{~J}(\mathrm{H}, \mathrm{H})=2.0 \mathrm{~Hz}, 1 \mathrm{H}\right), 4.60(\mathrm{~s}, 2 \mathrm{H}), 1.52(\mathrm{~s}, 9 \mathrm{H}) ;{ }^{13} \mathrm{C}$ NMR $\left(100 \mathrm{MHz}, \mathrm{CDCl}_{3}\right): 169.0(\mathrm{~s})$, 156.3 (s), 153.6 (s), 135.3 (s), 127.2 (d), 126.8 (d), 123.3 (d), 122.2 (d), 121.4 (s), 101.9 (d), $99.3(\mathrm{~d}), 83.2(\mathrm{~s}), 65.8(\mathrm{t}), 28.3(\mathrm{q})$.

1,6- and 6,1-Isomer. The 1,6-isomer (1-hydroxy, 6-t-butoxycarbonylmethoxy) and the 6,1isomer (1-t-butoxycarbonylmethoxy, 6-hydroxy) could not be separated. Yield: $30 \%$ (as 1:1 mixture of isomers); ${ }^{1} \mathrm{H}$ NMR $\left(400 \mathrm{MHz}, \mathrm{CDCl}_{3}\right): 8.30\left(\mathrm{~d},{ }^{3} \mathrm{~J}(\mathrm{H}, \mathrm{H})=8.8 \mathrm{~Hz}, 1 \mathrm{H}\right), 8.16\left(\mathrm{~d},{ }^{3} \mathrm{~J}\right.$ $(\mathrm{H}, \mathrm{H})=8.8 \mathrm{~Hz}, 1 \mathrm{H}), 7.34-7.25(\mathrm{~m}, 5 \mathrm{H}), 7.15\left(\mathrm{~d},{ }^{3} J(\mathrm{H}, \mathrm{H})=2.4 \mathrm{~Hz}, 1 \mathrm{H}\right), 7.09\left(\mathrm{dd},{ }^{3} J(\mathrm{H}, \mathrm{H})=\right.$ $\left.9.6 \mathrm{~Hz},{ }^{3} J(\mathrm{H}, \mathrm{H})=2.4 \mathrm{~Hz}, 1 \mathrm{H}\right), 6.74\left(\mathrm{dd},{ }^{3} J(\mathrm{H}, \mathrm{H})=6.8 \mathrm{~Hz},{ }^{3} J(\mathrm{H}, \mathrm{H})=1.6 \mathrm{~Hz}, 1 \mathrm{H}\right), 6.59(\mathrm{dd}$, $\left.{ }^{3} J(\mathrm{H}, \mathrm{H})=5.6 \mathrm{~Hz},{ }^{3} J(\mathrm{H}, \mathrm{H})=3.2 \mathrm{~Hz}, 1 \mathrm{H}\right), 4.74(\mathrm{~s}, 2 \mathrm{H}), 4.69(\mathrm{~s}, 2 \mathrm{H}), 1.57(\mathrm{~s}, 9 \mathrm{H}) 1.56(\mathrm{~s}$, $9 \mathrm{H})$.

3,1-Isomer. The 1,3-isomer (1-hydroxy, 3-t-butoxycarbonylmethoxy) and the 3,1-isomer (1$t$-butoxycarbonylmethoxy, 3-hydroxy) were separated by column chromatography $\left(\mathrm{CH}_{2} \mathrm{Cl}_{2}, R_{\mathrm{f}}\right.$ $\left.(1,3)=0.14, R_{\mathrm{f}}(3,1)=0.16\right)$. Yield: $32 \% ;{ }^{1} \mathrm{H} \mathrm{NMR}\left(400 \mathrm{MHz}, \mathrm{CDCl}_{3}\right): 8.29\left(\mathrm{~d},{ }^{3} J(\mathrm{H}, \mathrm{H})=\right.$ $8.0 \mathrm{~Hz}, 1 \mathrm{H}), 7.64\left(\mathrm{~d},{ }^{3} J(\mathrm{H}, \mathrm{H})=8.0 \mathrm{~Hz}, 1 \mathrm{H}\right), 7.48\left(\mathrm{t},{ }^{3} J(\mathrm{H}, \mathrm{H})=8.0 \mathrm{~Hz}, 1 \mathrm{H}\right), 7.38\left(\mathrm{t},{ }^{3} J(\mathrm{H}, \mathrm{H})\right.$ $=8.0 \mathrm{~Hz}, 1 \mathrm{H}), 6.80(\mathrm{~s}, 1 \mathrm{H}), 6.43(\mathrm{~s}, 1 \mathrm{H}), 4.72(\mathrm{~s}, 2 \mathrm{H}), 1.57(\mathrm{~s}, 9 \mathrm{H}) ;{ }^{13} \mathrm{C} \mathrm{NMR}(100 \mathrm{MHz}$, $\mathrm{CDCl}_{3}$ ): 168.0 (s), 155.5 (s), 153.8 (s), 135.4 (s), 127.6 (d), 126.1 (d), 123.3 (d), 122.5 (d), $121.5(\mathrm{~s}), 102.8(\mathrm{~d}), 98.3(\mathrm{~d}), 82.8(\mathrm{~s}), 66.3(\mathrm{t}), 28.3(\mathrm{q})$.

2,6-Isomer. Yield: $21 \%$; ${ }^{1} \mathrm{H}$ NMR $\left(400 \mathrm{MHz}, \mathrm{CDCl}_{3}\right): 7.59\left(\mathrm{~d},{ }^{3} \mathrm{~J}(\mathrm{H}, \mathrm{H})=9.6 \mathrm{~Hz}, 1 \mathrm{H}\right), 7.55$ $\left(\mathrm{d},{ }^{3} J(\mathrm{H}, \mathrm{H})=9.2 \mathrm{~Hz}, 1 \mathrm{H}\right), 7.18\left(\mathrm{dd},{ }^{3} J(\mathrm{H}, \mathrm{H})=9.6 \mathrm{~Hz},{ }^{3} J(\mathrm{H}, \mathrm{H})=2.4 \mathrm{~Hz}, 1 \mathrm{H}\right), 7.08\left(\mathrm{~d},{ }^{3} J\right.$ $(\mathrm{H}, \mathrm{H})=2.4 \mathrm{~Hz}, 1 \mathrm{H}), 7.07\left(\mathrm{dd},{ }^{3} J(\mathrm{H}, \mathrm{H})=9.2 \mathrm{~Hz},{ }^{3} J(\mathrm{H}, \mathrm{H})=2.4 \mathrm{~Hz}, 1 \mathrm{H}\right), 7.01\left(\mathrm{~d},{ }^{3} J(\mathrm{H}, \mathrm{H})=\right.$ $2.4 \mathrm{~Hz}, 1 \mathrm{H}), 4.62(\mathrm{~s}, 2 \mathrm{H}), 1.52(\mathrm{~s}, 9 \mathrm{H}) ;{ }^{13} \mathrm{C} \mathrm{NMR}\left(100 \mathrm{MHz}, \mathrm{CDCl}_{3}\right): 168.6$ (s), 154.5 (s), 152.5 (s), 130.5 (s), 129.5 (s), 128.7 (d), 128.3 (d), 119.4 (d), 118.5 (d), 109.9 (d), 107.5 (d), $82.8(\mathrm{~s}), 66.1(\mathrm{t}), 28.3(\mathrm{q})$. 
Isomers 26 (see Table 1 for isomers). A solution of anindividualk isomer of $\mathbf{2 5}$ (770 mg, 2.8 $\mathrm{mmol})$, potassium carbonate $(500 \mathrm{mg}, 3.6 \mathrm{mmol})$ and methyl bromoacetate $(0.3 \mathrm{ml}, 3.4 \mathrm{mmol})$ in acetone $(10 \mathrm{ml})$ was heated to $70{ }^{\circ} \mathrm{C}$ and stirred overnight. After cooling, the mixture was filtrated and poured into $0.1 \mathrm{~N} \mathrm{HCl}$, extracted with EtOAc, washed with water (2 times) and brine, dried with anhydrous $\mathrm{Na}_{2} \mathrm{SO}_{4}$, filtered and concentrated. Purification of the crude product by column chromatography $\left(\mathrm{CH}_{2} \mathrm{Cl}_{2}\right)$ yielded the corresponding individual isomer 26 as a colorless solid. IR (neat): 2988 (w), 2955 (w), 1756 (s), 1597 (m), $1514(\mathrm{~m}), 1415$ (s), 1238 (m), 1208 (m), 1150 (s), 1106 (s), 1070 (m), 844 (m), 769 (s); ESI MS (MeOH/CH $\mathrm{Cl}_{2}$ 1:1): $365\left(27,\left[\mathrm{M}+\mathrm{NH}_{4}\right]^{+}\right), 347\left(15,[\mathrm{M}+\mathrm{H}]^{+}\right), 291\left(100,[\mathrm{M}-t-\mathrm{Bu}+\mathrm{H}]^{+}\right)$.

2,7-Isomer. Yield: $84 \% ;{ }^{1} \mathrm{H}$ NMR $\left(400 \mathrm{MHz}, \mathrm{CDCl}_{3}: 7.65\left(\mathrm{~d},{ }^{3} \mathrm{~J}(\mathrm{H}, \mathrm{H})=8.8 \mathrm{~Hz}, 1 \mathrm{H}\right), 7.65\right.$ $\left(\mathrm{d},{ }^{3} J(\mathrm{H}, \mathrm{H})=9.2 \mathrm{~Hz}, 1 \mathrm{H}\right), 7.22\left(\mathrm{dd},{ }^{3} J(\mathrm{H}, \mathrm{H})=8.8 \mathrm{~Hz},{ }^{3} J(\mathrm{H}, \mathrm{H})=1.6 \mathrm{~Hz}, 1 \mathrm{H}\right), 7.21\left(\mathrm{dd},{ }^{3} J\right.$ $\left.(\mathrm{H}, \mathrm{H})=8.8 \mathrm{~Hz},{ }^{3} J(\mathrm{H}, \mathrm{H})=1.6 \mathrm{~Hz}, 1 \mathrm{H}\right), 7.05\left(\mathrm{~d},{ }^{3} J(\mathrm{H}, \mathrm{H})=1.6 \mathrm{~Hz}, 1 \mathrm{H}\right), 7.04\left(\mathrm{~d},{ }^{3} J(\mathrm{H}, \mathrm{H})=\right.$ $1.6 \mathrm{~Hz}, 1 \mathrm{H}), 4.74(\mathrm{~s}, 2 \mathrm{H}), 4.61(\mathrm{~s}, 2 \mathrm{H}), 3.84(\mathrm{~s}, 3 \mathrm{H}), 1.51(\mathrm{~s}, 9 \mathrm{H}) ;{ }^{13} \mathrm{C}$ NMR $(100 \mathrm{MHz}$, $\mathrm{CDCl}_{3}$ ): $169.6(\mathrm{~s}), 168.2(\mathrm{~s}), 156.8(\mathrm{~s}), 156.6(\mathrm{~s}), 135.6(\mathrm{~s}), 129.8$ (d), $129.6(\mathrm{~d}), 125.4(\mathrm{~s})$, 116.8 (d), 116.5 (d), 106.8 (d), 106.8 (d), $82.7(\mathrm{~s}), 66.0(\mathrm{t}), 65.6(\mathrm{t}), 52.6(\mathrm{q}), 28.3$ (q).

1,7-Isomer. Yield: $96 \%$; ${ }^{1} \mathrm{H}$ NMR $\left(400 \mathrm{MHz}, \mathrm{CDCl}_{3}\right): 7.71\left(\mathrm{~d},{ }^{3} \mathrm{~J}(\mathrm{H}, \mathrm{H})=8.8 \mathrm{~Hz}, 1 \mathrm{H}\right), 7.54$ $\left(\mathrm{d},{ }^{3} J(\mathrm{H}, \mathrm{H})=2.8 \mathrm{~Hz}, 1 \mathrm{H}\right), 7.40\left(\mathrm{~d},{ }^{3} J(\mathrm{H}, \mathrm{H})=8.0 \mathrm{~Hz}, 1 \mathrm{H}\right), 7.23\left(\mathrm{dd},{ }^{3} J(\mathrm{H}, \mathrm{H})=8.8 \mathrm{~Hz},{ }^{3} J\right.$ $(\mathrm{H}, \mathrm{H})=2.8 \mathrm{~Hz}, 1 \mathrm{H}), 7.21\left(\mathrm{t},{ }^{3} J(\mathrm{H}, \mathrm{H})=8.0 \mathrm{~Hz}, 1 \mathrm{H}\right), 6.68\left(\mathrm{~d},{ }^{3} J(\mathrm{H}, \mathrm{H})=8.0 \mathrm{~Hz}, 1 \mathrm{H}\right), 4.79(\mathrm{~s}$, 2H), 4.65 (s, 2H), $3.81(\mathrm{~s}, 3 \mathrm{H}), 1.49(\mathrm{~s}, 9 \mathrm{H}) ;{ }^{13} \mathrm{C}$ NMR (100 MHz, $\left.\mathrm{CDCl}_{3}\right): 169.6$ (s), 168.2 (s), 156.0 (s), 153.0 (s), 130.6 (s), 129.5 (d), 126.4 (s), 123.7 (d), 121.5 (d), 119.7 (d), 105.9 (d), $101.7(\mathrm{~d}), 82.6(\mathrm{~s}), 66.0(\mathrm{t}), 65.9(\mathrm{t}), 52.5(\mathrm{q}), 28.3(\mathrm{q})$.

7,1-Isomer. Yield: 97\%; ${ }^{1} \mathrm{H}$ NMR $\left(400 \mathrm{MHz}, \mathrm{CDCl}_{3}\right): 7.72\left(\mathrm{~d},{ }^{3} \mathrm{~J}(\mathrm{H}, \mathrm{H})=8.8 \mathrm{~Hz}, 1 \mathrm{H}\right), 7.57$ $\left(\mathrm{d},{ }^{3} J(\mathrm{H}, \mathrm{H})=2.8 \mathrm{~Hz}, 1 \mathrm{H}\right), 7.39\left(\mathrm{~d},{ }^{3} J(\mathrm{H}, \mathrm{H})=8.0 \mathrm{~Hz}, 1 \mathrm{H}\right), 7.24\left(\mathrm{dd},{ }^{3} J(\mathrm{H}, \mathrm{H})=8.8 \mathrm{~Hz},{ }^{3} J\right.$ $(\mathrm{H}, \mathrm{H})=2.8 \mathrm{~Hz}, 1 \mathrm{H}), 7.21\left(\mathrm{t},{ }^{3} J(\mathrm{H}, \mathrm{H})=8.0 \mathrm{~Hz}, 1 \mathrm{H}\right), 6.67\left(\mathrm{~d},{ }^{3} J(\mathrm{H}, \mathrm{H})=8.0 \mathrm{~Hz}, 1 \mathrm{H}\right), 4.78(\mathrm{~s}$, 2H), 4.67 (s, 2H), 3.82 (s, 3H), 1.48 (s, 9H); ${ }^{13} \mathrm{C}$ NMR (100 MHz, $\mathrm{CDCl}_{3}$ ): 169.5 (s), 168.2 (s), 155.8 (s), 153.2 (s), 130.7 (s), 129.6 (d), 126.5 (s), 123.9 (d), 121.2 (d), 119.5 (d), 105.9 $(\mathrm{d}), 101.8(\mathrm{~d}), 82.6(\mathrm{~s}), 66.4(\mathrm{t}), 65.5(\mathrm{t}), 52.5(\mathrm{q}), 28.3(\mathrm{q})$.

2,3-Isomer. Yield: 86\%; ${ }^{1} \mathrm{H}$ NMR (400 MHz, $\mathrm{CDCl}_{3}$ ): 7.66-7.62 (m, 2H), 7.35-7.30 (m, 2H), $7.10(\mathrm{~s}, 1 \mathrm{H}), 7.05(\mathrm{~s}, 1 \mathrm{H}), 4.82(\mathrm{~s}, 2 \mathrm{H}), 4.69(\mathrm{~s}, 2 \mathrm{H}), 3.80(\mathrm{~s}, 3 \mathrm{H}), 1.47(\mathrm{~s}, 9 \mathrm{H}) ;{ }^{13} \mathrm{C} \mathrm{NMR}$ $\left(100 \mathrm{MHz}, \mathrm{CDCl}_{3}\right)$ : 169.5 (s), 167.8 (s), 148.1 (s), 147.9 (s), 129.8 (s), 129.5 (S), 126.8 (d), 126.7 (d), 125.1 (d), 124.9 (d), 109.9 (d), 109.1 (d), 82.7 (s), 66.6 (t), 66.5 (t), 52.6 (q), 28.3 (q).

1,4-Isomer. Yield: 67\%; ${ }^{1} \mathrm{H}$ NMR (400 MHz, $\left.\mathrm{CDCl}_{3}\right)$ : 8.31-8.26 (m, 2H), 7.53-7.50 (m, $2 \mathrm{H}), 6.58\left(\mathrm{~d},{ }^{3} \mathrm{~J}(\mathrm{H}, \mathrm{H})=8.4 \mathrm{~Hz}, 1 \mathrm{H}\right), 6.55\left(\mathrm{~d},{ }^{3} \mathrm{~J}(\mathrm{H}, \mathrm{H})=8.4 \mathrm{~Hz}, 1 \mathrm{H}\right), 4.75(\mathrm{~s}, 2 \mathrm{H}), 4.63(\mathrm{~s}$, 2H), 3.81 (s, 3H), 1.48 (s, 9H); ${ }^{13} \mathrm{C}$ NMR (100 MHz, $\mathrm{CDCl}_{3}$ ): 169.8 (s), 168.3 (s), 149.0 (s), 148.6 (s), 126.7 (s), 126.7 (s), 126.6 (d), 126.6 (d), 122.3 (d), 122.1 (d), 104.9 (d), 104.6 (d), $82.5(\mathrm{~s}), 66.7(\mathrm{t}), 66.4(\mathrm{t}), 52.5(\mathrm{q}), 28.3(\mathrm{q})$.

1,3-Isomer. Yield: 77\%; ${ }^{1} \mathrm{H}$ NMR (400 MHz, $\left.\mathrm{CDCl}_{3}\right): 8.25\left(\mathrm{~d},{ }^{3} \mathrm{~J}(\mathrm{H}, \mathrm{H})=8.4 \mathrm{~Hz}, 1 \mathrm{H}\right), 7.66$ $\left(\mathrm{d},{ }^{3} J(\mathrm{H}, \mathrm{H})=8.0 \mathrm{~Hz}, 1 \mathrm{H}\right), 7.47\left(\mathrm{dd},{ }^{3} J(\mathrm{H}, \mathrm{H})=8.0 \mathrm{~Hz},{ }^{3} J(\mathrm{H}, \mathrm{H})=2.0 \mathrm{~Hz}, 1 \mathrm{H}\right), 7.37\left(\mathrm{dd},{ }^{3} J\right.$ $\left.(\mathrm{H}, \mathrm{H})=8.4 \mathrm{~Hz},{ }^{3} J(\mathrm{H}, \mathrm{H})=2.0 \mathrm{~Hz}, 1 \mathrm{H}\right), 6.68\left(\mathrm{~d},{ }^{3} J(\mathrm{H}, \mathrm{H})=2.0 \mathrm{~Hz}, 1 \mathrm{H}\right), 6.52\left(\mathrm{~d},{ }^{3} J(\mathrm{H}, \mathrm{H})=\right.$ $2.0 \mathrm{~Hz}, 1 \mathrm{H}), 4.81(\mathrm{~s}, 2 \mathrm{H}), 4.61(\mathrm{~s}, 2 \mathrm{H}), 3.85(\mathrm{~s}, 3 \mathrm{H}), 1.52(\mathrm{~s}, 9 \mathrm{H}) ;{ }^{13} \mathrm{C}$ NMR $(100 \mathrm{MHz}$, 
$\mathrm{CDCl}_{3}$ ): 169.2 (s), 168.0 (s), 156.1 (s), 155.0 (s), 135.1 (s), 127.6 (d), 126.7 (d), 123.9 (d), 122.4 (d), 122.1 (s), 100.1(d), 99.1 (d), 82.8 (s), 65.9 (t), 65.7 (t), 52.6 (q), 28.3 (q).

1,6- and 6,1-Isomer. The 1,6-isomer and the 6,1-isomer could not be separated. Yield: $88 \%$ (as 1:1 mixture of isomers); ${ }^{1} \mathrm{H}$ NMR $\left(400 \mathrm{MHz}, \mathrm{CDCl}_{3}\right): 8.28\left(\mathrm{~d},{ }^{3} \mathrm{~J}(\mathrm{H}, \mathrm{H})=9.2 \mathrm{~Hz}, 1 \mathrm{H}\right)$, $8.26\left(\mathrm{~d},{ }^{3} J(\mathrm{H}, \mathrm{H})=9.2 \mathrm{~Hz}, 1 \mathrm{H}\right), 7.32\left(\mathrm{~d},{ }^{3} J(\mathrm{H}, \mathrm{H})=7.2 \mathrm{~Hz}, 2 \mathrm{H}\right), 7.28\left(\mathrm{dd},{ }^{3} J(\mathrm{H}, \mathrm{H})=8.4 \mathrm{~Hz}\right.$, $\left.{ }^{3} J(\mathrm{H}, \mathrm{H})=2.0 \mathrm{~Hz}, 2 \mathrm{H}\right), 7.20\left(\mathrm{dd},{ }^{3} J(\mathrm{H}, \mathrm{H})=9.2 \mathrm{~Hz},{ }^{3} J(\mathrm{H}, \mathrm{H})=2.8 \mathrm{~Hz}, 1 \mathrm{H}\right), 7.19\left(\mathrm{dd},{ }^{3} J\right.$ $\left.(\mathrm{H}, \mathrm{H})=9.2 \mathrm{~Hz},{ }^{3} J(\mathrm{H}, \mathrm{H})=2.8 \mathrm{~Hz}, 1 \mathrm{H}\right), 7.02(\mathrm{~s}, 2 \mathrm{H}), 6.5\left(\mathrm{~d},{ }^{3} J(\mathrm{H}, \mathrm{H})=6.8 \mathrm{~Hz}, 2 \mathrm{H}\right), 4.78(\mathrm{~s}$, $2 \mathrm{H}), 4.73(\mathrm{~s}, 2 \mathrm{H}), 4.66(\mathrm{~s}, 2 \mathrm{H}), 4.61(\mathrm{~s}, 2 \mathrm{H}), 1.48(\mathrm{~s}, 9 \mathrm{H}) 1.48(\mathrm{~s}, 9 \mathrm{H})$.

3,1-Isomer. Yield: 91\%; ${ }^{1} \mathrm{H}$ NMR $\left(400 \mathrm{MHz}, \mathrm{CDCl}_{3}\right): 8.24\left(\mathrm{~d},{ }^{3} J(\mathrm{H}, \mathrm{H})=8.4 \mathrm{~Hz}, 1 \mathrm{H}\right), 7.64$ $\left(\mathrm{d},{ }^{3} J(\mathrm{H}, \mathrm{H})=8.0 \mathrm{~Hz}, 1 \mathrm{H}\right), 7.44\left(\mathrm{dd},{ }^{3} J(\mathrm{H}, \mathrm{H})=8.0 \mathrm{~Hz},{ }^{3} J(\mathrm{H}, \mathrm{H})=2.0 \mathrm{~Hz}, 1 \mathrm{H}\right), 7.34\left(\mathrm{dd},{ }^{3} J\right.$ $\left.(\mathrm{H}, \mathrm{H})=8.4 \mathrm{~Hz},{ }^{3} J(\mathrm{H}, \mathrm{H})=2.0 \mathrm{~Hz}, 1 \mathrm{H}\right), 6.64\left(\mathrm{~d},{ }^{3} J(\mathrm{H}, \mathrm{H})=2.0 \mathrm{~Hz}, 1 \mathrm{H}\right), 6.48\left(\mathrm{~d},{ }^{3} J(\mathrm{H}, \mathrm{H})=\right.$ $2.0 \mathrm{~Hz}, 1 \mathrm{H}), 4.71(\mathrm{~s}, 2 \mathrm{H}), 4.65(\mathrm{~s}, 2 \mathrm{H}), 3.81(\mathrm{~s}, 3 \mathrm{H}), 1.50(\mathrm{~s}, 9 \mathrm{H}) ;{ }^{13} \mathrm{C}$ NMR $(100 \mathrm{MHz}$, $\mathrm{CDCl}_{3}$ ): 169.5 (s), 167.7 (s), 156.1 (s), 155.3 (s), 135.0 (s), 127.6 (d), 126.7 (d), 123.9 (d), 122.5 (d), 122.3 (s), 99.9 (d), 99.0 (d), 82.8 (s), 66.2 (t), 65.5 (t), 52.6 (q), 28.3 (q).

2,6-Isomer. Yield: $83 \%$; ${ }^{1} \mathrm{H}$ NMR $\left(400 \mathrm{MHz}, \mathrm{CDCl}_{3}\right)$ : $7.65\left(\mathrm{~d},{ }^{3} \mathrm{~J}(\mathrm{H}, \mathrm{H})=8.8 \mathrm{~Hz}, 1 \mathrm{H}\right), 7.65$ $\left(\mathrm{d},{ }^{3} J(\mathrm{H}, \mathrm{H})=9.2 \mathrm{~Hz}, 1 \mathrm{H}\right), 7.22\left(\mathrm{dd},{ }^{3} J(\mathrm{H}, \mathrm{H})=8.8 \mathrm{~Hz},{ }^{3} J(\mathrm{H}, \mathrm{H})=1.6 \mathrm{~Hz}, 1 \mathrm{H}\right), 7.21\left(\mathrm{dd},{ }^{3} J\right.$ $\left.(\mathrm{H}, \mathrm{H})=8.8 \mathrm{~Hz},{ }^{3} J(\mathrm{H}, \mathrm{H})=1.6 \mathrm{~Hz}, 1 \mathrm{H}\right), 7.05\left(\mathrm{~d},{ }^{3} J(\mathrm{H}, \mathrm{H})=1.6 \mathrm{~Hz}, 1 \mathrm{H}\right), 7.04\left(\mathrm{~d},{ }^{3} J(\mathrm{H}, \mathrm{H})=\right.$ $1.6 \mathrm{~Hz}, 1 \mathrm{H}), 4.74(\mathrm{~s}, 2 \mathrm{H}), 4.61(\mathrm{~s}, 2 \mathrm{H}), 3.84(\mathrm{~s}, 3 \mathrm{H}), 1.51(\mathrm{~s}, 9 \mathrm{H}) ;{ }^{13} \mathrm{C}$ NMR $(100 \mathrm{MHz}$, $\mathrm{CDCl}_{3}$ ): 169.6 (s), 168.2 (s), 155.0 (s), 154.7 (s), 130.3 (s), 130.1 (s), 128.8 (d), 128.8 (d), 119.4 (d), 119.2 (d), 107.6 (d), $107.6(\mathrm{~d}), 82.6(\mathrm{~s}), 66.0(\mathrm{t}), 65.7(\mathrm{t}), 52.6(\mathrm{q}), 28.3(\mathrm{q})$.

Isomers 27 (see Table 1 for isomers). A solution of an individual isomer $\mathbf{2 6}$ (200 $\mathrm{mg}, 0.58$ mmol) in $\mathrm{CH}_{2} \mathrm{Cl}_{2}(3 \mathrm{ml})$, TFA (3 ml) was added at rt. After stirring $2 \mathrm{hrs}$ at $\mathrm{rt}$, the solvent was evaporated to yield the corresponding individual isomer 27. IR (neat): $2988(\mathrm{w}), 2909$ (w), 1771 (m), 1738 (m), 1601 (m), 1511 (m), 1435 (s), 1385 (m), 1231 (m), 1207 (m), 1163 (s), 1118 (s), 1077 (m), 856 (m), 738 (m); ESI MS (DMSO/TFA 3:1): $291\left(100,[\mathrm{M}+\mathrm{H}]^{+}\right)$.

2,7-Isomer. Yield: 97\%; ${ }^{1} \mathrm{H}$ NMR $\left(400 \mathrm{MHz}, \mathrm{DMSO}-d_{6}\right): 7.76\left(\mathrm{~d},{ }^{3} J(\mathrm{H}, \mathrm{H})=8.8 \mathrm{~Hz}, 2 \mathrm{H}\right)$, $7.18\left(\mathrm{~d},{ }^{3} J(\mathrm{H}, \mathrm{H})=2.0 \mathrm{~Hz}, 1 \mathrm{H}\right), 7.14\left(\mathrm{~d},{ }^{3} J(\mathrm{H}, \mathrm{H})=1.6 \mathrm{~Hz}, 1 \mathrm{H}\right), 7.05\left(\mathrm{dd},{ }^{3} J(\mathrm{H}, \mathrm{H})=8.8 \mathrm{~Hz}\right.$, $\left.{ }^{3} J(\mathrm{H}, \mathrm{H})=2.0 \mathrm{~Hz}, 1 \mathrm{H}\right), 7.03\left(\mathrm{dd},{ }^{3} J(\mathrm{H}, \mathrm{H})=8.8 \mathrm{~Hz},{ }^{3} J(\mathrm{H}, \mathrm{H})=2.0 \mathrm{~Hz}, 1 \mathrm{H}\right), 4.90(\mathrm{~s}, 2 \mathrm{H}), 4.77$ (s, 2H), 3.73 (s, 3H); ${ }^{13} \mathrm{C}$ NMR (100 MHz, DMSO- $d_{6}$ ): 170.2 (s), 169.2 (s), 156.2 (s), 156.0 (s), 135.3 (s), 129.2 (d), 129.1 (d), 124.3 (s), 116.1 (d), 115.9 (d), 106.5 (d), 106.4 (d), 64.5 (t), $64.4(\mathrm{t}), 51.8(\mathrm{q})$.

1,7-Isomer. Yield: quant.; ${ }^{1} \mathrm{H}$ NMR $\left(400 \mathrm{MHz}, \mathrm{DMSO}-d_{6}\right): 7.85\left(\mathrm{~d},{ }^{3} J(\mathrm{H}, \mathrm{H})=8.8 \mathrm{~Hz}, 1 \mathrm{H}\right)$, $7.47\left(\mathrm{~d},{ }^{3} J(\mathrm{H}, \mathrm{H})=2.8 \mathrm{~Hz}, 1 \mathrm{H}\right), 7.45\left(\mathrm{~d},{ }^{3} J(\mathrm{H}, \mathrm{H})=8.0 \mathrm{~Hz}, 1 \mathrm{H}\right), 7.26\left(\mathrm{t},{ }^{3} J(\mathrm{H}, \mathrm{H})=8.0 \mathrm{~Hz}\right.$, $1 \mathrm{H}), 7.25\left(\mathrm{dd},{ }^{3} J(\mathrm{H}, \mathrm{H})=8.8 \mathrm{~Hz},{ }^{3} J(\mathrm{H}, \mathrm{H})=2.8 \mathrm{~Hz}, 1 \mathrm{H}\right), 6.87\left(\mathrm{~d},{ }^{3} J(\mathrm{H}, \mathrm{H})=8.0 \mathrm{~Hz}, 1 \mathrm{H}\right)$, $5.00(\mathrm{~s}, 2 \mathrm{H}), 4.80(\mathrm{~s}, 2 \mathrm{H}), 3.74(\mathrm{~s}, 3 \mathrm{H}) ;{ }^{13} \mathrm{C}$ NMR (100 MHz, DMSO- $\left.d_{6}\right): 170.0(\mathrm{~s}), 169.2(\mathrm{~s})$, 155.5 (s), 152.2 (s), 129.7 (s), 129.4 (d), 125.6 (s), 123.7 (d), 120.5 (d), 118.7 (d), 106.1 (d), $101.2(\mathrm{~d}), 65.0(\mathrm{t}), 64.6(\mathrm{t}), 51.9(\mathrm{q})$.

7,1-Isomer. Yield: quant.; ${ }^{1} \mathrm{H}$ NMR (400 MHz, DMSO- $\left.d_{6}\right): 7.84\left(\mathrm{~d},{ }^{3} J(\mathrm{H}, \mathrm{H})=8.8 \mathrm{~Hz}, 1 \mathrm{H}\right)$, $7.46\left(\mathrm{~d},{ }^{3} J(\mathrm{H}, \mathrm{H})=2.8 \mathrm{~Hz}, 1 \mathrm{H}\right), 7.45\left(\mathrm{~d},{ }^{3} J(\mathrm{H}, \mathrm{H})=8.0 \mathrm{~Hz}, 1 \mathrm{H}\right), 7.27\left(\mathrm{t},{ }^{3} J(\mathrm{H}, \mathrm{H})=8.0 \mathrm{~Hz}\right.$, $1 \mathrm{H}), 7.25\left(\mathrm{dd},{ }^{3} J(\mathrm{H}, \mathrm{H})=8.8 \mathrm{~Hz},{ }^{3} J(\mathrm{H}, \mathrm{H})=2.8 \mathrm{~Hz}, 1 \mathrm{H}\right), 6.86\left(\mathrm{~d},{ }^{3} J(\mathrm{H}, \mathrm{H})=8.0 \mathrm{~Hz}, 1 \mathrm{H}\right)$, 4.92 (s, 2H), 4.87 (s, 2H), 3.73 (s, 3H); ${ }^{13} \mathrm{C}$ NMR (100 MHz, DMSO- $\left.d_{6}\right)$ : $170.1(\mathrm{~s}), 169.2$ (s), 
155.3 (s), 152.4 (s), 129.8 (s), 129.4 (d), 125.6 (s), 123.9 (d), 120.3 (d), 118.5 (d), 106.0 (d), $101.6(\mathrm{~d}), 65.0(\mathrm{t}), 64.8(\mathrm{t}), 51.9(\mathrm{q})$.

2,3-Isomer. Yield: quant.; ${ }^{1} \mathrm{H}$ NMR (400 MHz, DMSO- $\left.d_{6}\right)$ : 7.73-7.71 (m, 2H), 7.34-7.32 $(\mathrm{m}, 2 \mathrm{H}), 7.28(\mathrm{~s}, 1 \mathrm{H}), 7.26(\mathrm{~s}, 1 \mathrm{H}), 4.95(\mathrm{~s}, 2 \mathrm{H}), 4.84(\mathrm{~s}, 2 \mathrm{H}), 3.73(\mathrm{~s}, 3 \mathrm{H}) ;{ }^{13} \mathrm{C}$ NMR $(100$ MHz, DMSO-d $d_{6}$ ): 169.9 (s), 169.0 (s), 147.5 (s), 147.4 (s), 129.0 (s), 128.8 (s), 126.4 (d), 126.3 (d), 124.4 (d), 124.3 (d), 108.5 (d), 108.1 (d), 65.0 (t), 64.8 (t), 51.9 (q).

1,4-Isomer. Yield: quant.; ${ }^{1} \mathrm{H}$ NMR (400 MHz, DMSO- $\left.d_{6}\right)$ : 8.20-8.17 (m, 2H), 7.59-7.57 $(\mathrm{m}, 2 \mathrm{H}), 6.79\left(\mathrm{~d},{ }^{3} J(\mathrm{H}, \mathrm{H})=8.4 \mathrm{~Hz}, 1 \mathrm{H}\right), 6.75\left(\mathrm{~d},{ }^{3} J(\mathrm{H}, \mathrm{H})=8.4 \mathrm{~Hz}, 1 \mathrm{H}\right), 4.94(\mathrm{~s}, 2 \mathrm{H}), 4.82$ $(\mathrm{s}, 2 \mathrm{H}), 3.73(\mathrm{~s}, 3 \mathrm{H}) ;{ }^{13} \mathrm{C}$ NMR (100 MHz, DMSO-d $\left.d_{6}\right): 170.3(\mathrm{~s}), 169.3$ (s), 147.6 (s), 147.2 (s), 126.2 (d), 126.1 (d), 125.6 (s), 125.6 (s), 121.6 (d), 121.5 (d), 105.1 (d), 104.8 (d), 65.2 $(\mathrm{t}), 65.1(\mathrm{t}), 51.9(\mathrm{q})$.

1,3-Isomer. Yield: 98\%; ${ }^{1} \mathrm{H}$ NMR (400 MHz, DMSO- $\left.d_{6}\right): 8.09\left(\mathrm{~d},{ }^{3} J(\mathrm{H}, \mathrm{H})=8.4 \mathrm{~Hz}, 1 \mathrm{H}\right)$, $7.76\left(\mathrm{~d},{ }^{3} J(\mathrm{H}, \mathrm{H})=8.0 \mathrm{~Hz}, 1 \mathrm{H}\right), 7.49\left(\mathrm{t},{ }^{3} J(\mathrm{H}, \mathrm{H})=8.0 \mathrm{~Hz}, 1 \mathrm{H}\right), 7.37\left(\mathrm{~d},{ }^{3} J(\mathrm{H}, \mathrm{H})=8.4 \mathrm{~Hz}\right.$, $1 \mathrm{H}), 6.88\left(\mathrm{~d},{ }^{3} J(\mathrm{H}, \mathrm{H})=2.0 \mathrm{~Hz}, 1 \mathrm{H}\right), 6.62\left(\mathrm{~d},{ }^{3} J(\mathrm{H}, \mathrm{H})=2.0 \mathrm{~Hz}, 1 \mathrm{H}\right), 5.03(\mathrm{~s}, 2 \mathrm{H}), 4.78(\mathrm{~s}$, 2H), 3.75 (s, 3H); ${ }^{13} \mathrm{C}$ NMR (100 MHz, DMSO- $\left.d_{6}\right)$ : $170.0(\mathrm{~s}), 169.0$ (s), 155.9 (s), 154.1 (s), 134.6 (s), 127.2 (d), 126.6 (d), 123.3 (d), 121.5 (d), 120.9 (s), 99.8 (d), 98.9 (d), 65.0 (t), 64.6 $(\mathrm{t}), 51.9(\mathrm{q})$.

1,6-Isomer. The 1,6-isomer was separated from the 6,1-isomer by recrystallization from EtOH. ${ }^{1} \mathrm{H}$ NMR (400 MHz, CD $\left.\mathrm{OD}\right): 8.07\left(\mathrm{~d},{ }^{3} J(\mathrm{H}, \mathrm{H})=9.2 \mathrm{~Hz}, 1 \mathrm{H}\right), 7.31\left(\mathrm{dd},{ }^{3} J(\mathrm{H}, \mathrm{H})=\right.$ $\left.8.4 \mathrm{~Hz},{ }^{3} J(\mathrm{H}, \mathrm{H})=2.0 \mathrm{~Hz}, 1 \mathrm{H}\right), 7.27\left(\mathrm{dd},{ }^{3} J(\mathrm{H}, \mathrm{H})=8.4 \mathrm{~Hz},{ }^{3} J(\mathrm{H}, \mathrm{H})=6.4 \mathrm{~Hz}, 1 \mathrm{H}\right), 7.14(\mathrm{dd}$, $\left.{ }^{3} J(\mathrm{H}, \mathrm{H})=9.2 \mathrm{~Hz},{ }^{3} J(\mathrm{H}, \mathrm{H})=2.4 \mathrm{~Hz}, 1 \mathrm{H}\right), 7.09\left(\mathrm{~d},{ }^{3} J(\mathrm{H}, \mathrm{H})=2.4 \mathrm{~Hz}, 1 \mathrm{H}\right), 6.69\left(\mathrm{dd},{ }^{3} J(\mathrm{H}, \mathrm{H})\right.$ $\left.=6.4 \mathrm{~Hz},{ }^{3} \mathrm{~J}(\mathrm{H}, \mathrm{H})=2.0 \mathrm{~Hz}, 1 \mathrm{H}\right), 4.97(\mathrm{~s}, 2 \mathrm{H}), 4.34(\mathrm{~s}, 2 \mathrm{H}), 3.73(\mathrm{~s}, 3 \mathrm{H}) ;{ }^{13} \mathrm{C} \mathrm{NMR}(100$ $\mathrm{MHz}, \mathrm{CD}_{3} \mathrm{OD}$ ): 171.2 (s), 169.2 (s), 157.4 (s), 153.2 (s), 135.6 (s), 126.4 (d), 122.8 (d), 119.7 (d), $118.2(d), 106.8(d), 103.0(d), 65.8(t), 64.8(t), 51.9(q)$.

3,1-Isomer. Yield: 98\%; ${ }^{1} \mathrm{H}$ NMR $\left(400 \mathrm{MHz}, \mathrm{DMSO}-d_{6}\right): 8.10\left(\mathrm{~d},{ }^{3} J(\mathrm{H}, \mathrm{H})=8.4 \mathrm{~Hz}, 1 \mathrm{H}\right)$, $7.75\left(\mathrm{~d},{ }^{3} J(\mathrm{H}, \mathrm{H})=8.0 \mathrm{~Hz}, 1 \mathrm{H}\right), 7.49\left(\mathrm{t},{ }^{3} J(\mathrm{H}, \mathrm{H})=8.0 \mathrm{~Hz}, 1 \mathrm{H}\right), 7.37\left(\mathrm{~d},{ }^{3} J(\mathrm{H}, \mathrm{H})=8.4 \mathrm{~Hz}\right.$, $1 \mathrm{H}), 6.89\left(\mathrm{~d},{ }^{3} J(\mathrm{H}, \mathrm{H})=2.0 \mathrm{~Hz}, 1 \mathrm{H}\right), 6.59\left(\mathrm{~d},{ }^{3} J(\mathrm{H}, \mathrm{H})=2.0 \mathrm{~Hz}, 1 \mathrm{H}\right), 4.91(\mathrm{~s}, 2 \mathrm{H}), 4.90(\mathrm{~s}$, 2H), 3.74 (s, 3H); ${ }^{13} \mathrm{C}$ NMR (100 MHz, DMSO- $\left.d_{6}\right)$ : 169.9 (s), 169.1 (s), $155.8(\mathrm{~s}), 154.4$ (s), 134.5 (s), 127.2 (d), 126.7 (d), 123.3 (d), 121.6 (d), 121.1 (s), 99.7 (d), 98.7 (d), 65.0 (t), 64.7 $(\mathrm{t}), 51.9(\mathrm{q})$.

2,6-Isomer. Yield: quant.; ${ }^{1} \mathrm{H}$ NMR (400 MHz, DMSO- $\left.d_{6}\right): 7.74\left(\mathrm{~d},{ }^{3} J(\mathrm{H}, \mathrm{H})=8.8 \mathrm{~Hz}, 1 \mathrm{H}\right)$, $7.72\left(\mathrm{~d},{ }^{3} J(\mathrm{H}, \mathrm{H})=8.8 \mathrm{~Hz}, 1 \mathrm{H}\right), 7.26\left(\mathrm{~d},{ }^{3} J(\mathrm{H}, \mathrm{H})=2.4 \mathrm{~Hz}, 1 \mathrm{H}\right), 7.23\left(\mathrm{~d},{ }^{3} J(\mathrm{H}, \mathrm{H})=2.4 \mathrm{~Hz}\right.$, $1 \mathrm{H}), 7.19\left(\mathrm{dd},{ }^{3} J(\mathrm{H}, \mathrm{H})=8.8 \mathrm{~Hz},{ }^{3} J(\mathrm{H}, \mathrm{H})=2.4 \mathrm{~Hz}, 1 \mathrm{H}\right), 7.17\left(\mathrm{dd},{ }^{3} J(\mathrm{H}, \mathrm{H})=8.8 \mathrm{~Hz},{ }^{3} J\right.$ $(\mathrm{H}, \mathrm{H})=2.4 \mathrm{~Hz}, 1 \mathrm{H}), 4.88(\mathrm{~s}, 2 \mathrm{H}), 4.76(\mathrm{~s}, 2 \mathrm{H}), 3.72(\mathrm{~s}, 3 \mathrm{H}) ;{ }^{13} \mathrm{C}$ NMR (100 MHz, DMSO$\left.d_{6}\right): \quad 170.2(\mathrm{~s}), 169.2(\mathrm{~s}), 154.3(\mathrm{~s}), 154.0(\mathrm{~s}), 129.5(\mathrm{~s}), 129.4(\mathrm{~s}), 128.3(\mathrm{~d}), 128.3(\mathrm{~d}), 118.8$ (d), $118.7(d), 107.4(d), 107.2(d), 64.6(t), 64.5(t), 51.8(q)$.

Isomers 5-13 (see Table 1 for isomers). A solution of an individual isomer 27 (120 mg, 0.41 $\mathrm{mmol})$ in $\mathrm{MeOH}(5 \mathrm{ml})$, hydrazine monohydrate $(1 \mathrm{ml})$ was added at $\mathrm{rt}$. The mixture was heated to $70^{\circ} \mathrm{C}$ and stirred overnight. After cooling, the precipitate was subjected to solid/liquid extraction with $\mathrm{MeOH}$, filtered and washed with $\mathrm{MeOH}$ to give yielded the corresponding individual isomer 5-13 as colorless solids. IR (neat): 3305 (w), 2916 (w), 
2649 (w), 1665 (m), 1594 (m), 1557 (m), 1507 (s), 1440 (m), 1408 (s), 1371 (m), 1334 (m), 1264 (s), 1211 (m), 1090 (s), 1071 (s), 1017 (m), 944 (m), 909 (m), 778 (s), 712 (m); ESI MS (DMSO/TFA 3:1): $291\left(100,[\mathrm{M}+\mathrm{H}]^{+}\right), 273\left(90,[\mathrm{M}-\mathrm{NH}+\mathrm{H}]^{+}\right)$.

2,7-Isomer 5. Yield: quant.; ${ }^{1} \mathrm{H}$ NMR (400 MHz, DMSO- $\left.d_{6} / \mathrm{TFA}-d_{1} 2 / 1\right): 7.81\left(\mathrm{~d},{ }^{3} J(\mathrm{H}, \mathrm{H})\right.$ $=8.8 \mathrm{~Hz}, 1 \mathrm{H}), 7.78\left(\mathrm{~d},{ }^{3} J(\mathrm{H}, \mathrm{H})=8.8 \mathrm{~Hz}, 1 \mathrm{H}\right), 7.22\left(\mathrm{~d},{ }^{3} J(\mathrm{H}, \mathrm{H})=2.0 \mathrm{~Hz}, 2 \mathrm{H}\right), 7.12\left(\mathrm{~d},{ }^{3} J\right.$ $(\mathrm{H}, \mathrm{H})=2.0 \mathrm{~Hz}, 1 \mathrm{H}), 7.09\left(\mathrm{dd},{ }^{3} J(\mathrm{H}, \mathrm{H})=8.8 \mathrm{~Hz},{ }^{3} J(\mathrm{H}, \mathrm{H})=2.0 \mathrm{~Hz}, 1 \mathrm{H}\right), 7.07\left(\mathrm{dd},{ }^{3} J(\mathrm{H}, \mathrm{H})=\right.$ $\left.8.8 \mathrm{~Hz},{ }^{3} \mathrm{~J}(\mathrm{H}, \mathrm{H})=2.0 \mathrm{~Hz}, 1 \mathrm{H}\right), 4.85(\mathrm{~s}, 2 \mathrm{H}), 4.78(\mathrm{~s}, 2 \mathrm{H}) ;{ }^{13} \mathrm{C}$ NMR $(100 \mathrm{MHz}, \mathrm{DMSO}-$ $d_{6} /$ TFA- $d_{1}$ 2/1): $170.1(\mathrm{~s}), 167.3(\mathrm{~s}), 156.3(\mathrm{~s}), 155.9(\mathrm{~s}), 135.2(\mathrm{~s}), 129.3$ (d), 124.4 (d), 124.9 $(\mathrm{s}), 116.3(\mathrm{~d}), 116.0(\mathrm{~d}), 106.7(\mathrm{~d}), 106.4(\mathrm{~d}), 65.6(\mathrm{t}), 64.5(\mathrm{t})$.

1,5-Isomer 2. This compound was prepared following previously reported procedures. ${ }^{\mathrm{S} 1}$

7,1-Isomer 6. Yield: $82 \%$; ${ }^{1} \mathrm{H}$ NMR $\left(400 \mathrm{MHz}, \mathrm{DMSO}-d_{6} / \mathrm{TFA}-d_{1} 2 / 1\right): 7.78\left(\mathrm{~d},{ }^{3} J(\mathrm{H}, \mathrm{H})=\right.$ $8.8 \mathrm{~Hz}, 1 \mathrm{H}), 7.54\left(\mathrm{~d},{ }^{3} J(\mathrm{H}, \mathrm{H})=2.4 \mathrm{~Hz}, 1 \mathrm{H}\right), 7.34\left(\mathrm{~d},{ }^{3} J(\mathrm{H}, \mathrm{H})=8.0 \mathrm{~Hz}, 2 \mathrm{H}\right), 7.24\left(\mathrm{dd},{ }^{3} J\right.$ $\left.(\mathrm{H}, \mathrm{H})=8.8 \mathrm{~Hz},{ }^{3} J(\mathrm{H}, \mathrm{H})=2.4 \mathrm{~Hz}, 1 \mathrm{H}\right), 7.19\left(\mathrm{t},{ }^{3} J(\mathrm{H}, \mathrm{H})=8.0 \mathrm{~Hz}, 1 \mathrm{H}\right), 6.74\left(\mathrm{~d},{ }^{3} J(\mathrm{H}, \mathrm{H})=\right.$ $8.0 \mathrm{~Hz}, 1 \mathrm{H}), 4.59(\mathrm{~s}, 2 \mathrm{H}), 4.47(\mathrm{~s}, 2 \mathrm{H}) ;{ }^{13} \mathrm{C}$ NMR (100 MHz, DMSO- $\left.d_{6} / \mathrm{TFA}-d_{1} 2 / 1\right): 166.5$ (s), 166.5 (s), 155.2 (s), 153.5 (s), 129.7 (s), 129.0 (d), 125.8 (s), 123.9 (d), 119.1 (d), 118.6 (d), $105.9(\mathrm{~d}), 101.8(\mathrm{~d}), 67.7(\mathrm{t}), 66.2(\mathrm{t})$.

1,7-Isomer 7. Yield: $85 \% ;{ }^{1} \mathrm{H}$ NMR $\left(400 \mathrm{MHz}, \mathrm{DMSO}-d_{6} / \mathrm{TFA}-d_{1} 2 / 1\right): 7.74\left(\mathrm{~d},{ }^{3} J(\mathrm{H}, \mathrm{H})=\right.$ $8.8 \mathrm{~Hz}, 1 \mathrm{H}), 7.52\left(\mathrm{~d},{ }^{3} J(\mathrm{H}, \mathrm{H})=2.4 \mathrm{~Hz}, 1 \mathrm{H}\right), 7.40\left(\mathrm{~d},{ }^{3} J(\mathrm{H}, \mathrm{H})=8.0 \mathrm{~Hz}, 1 \mathrm{H}\right), 7.19\left(\mathrm{t},{ }^{3} J(\mathrm{H}, \mathrm{H})\right.$ $=8.0 \mathrm{~Hz}, 1 \mathrm{H}), 7.17\left(\mathrm{dd},{ }^{3} J(\mathrm{H}, \mathrm{H})=8.8 \mathrm{~Hz},{ }^{3} J(\mathrm{H}, \mathrm{H})=2.4 \mathrm{~Hz}, 1 \mathrm{H}\right), 6.83\left(\mathrm{~d},{ }^{3} J(\mathrm{H}, \mathrm{H})=8.0 \mathrm{~Hz}\right.$, $1 \mathrm{H}), 4.66(\mathrm{~s}, 2 \mathrm{H}), 4.37$ (s, 2H); ${ }^{13} \mathrm{C}$ NMR (100 MHz, DMSO- $\left.d_{6} / \mathrm{TFA}-d_{1} 2 / 1\right): 171.6$ (s), 166.7 (s), 156.6 (s), 152.5 (s), 129.2 (s), 128.6 (d), 125.9 (s), 123.0 (d), 120.4 (d), 119.2 (d), 105.9 (d), $101.7(d), 67.6(t), 66.7(t)$.

2,3-Isomer 8. Yield: 97\%; ${ }^{1} \mathrm{H}$ NMR (400 MHz, DMSO- $\left.d_{6} / \mathrm{TFA}-d_{1} 2 / 1\right)$ : 7.75-7.68 (m, 2H), 7.36-7.34 (m, 2H), $7.32(\mathrm{~s}, 1 \mathrm{H}), 7.30(\mathrm{~s}, 1 \mathrm{H}), 4.87(\mathrm{~s}, 2 \mathrm{H}), 4.85(\mathrm{~s}, 2 \mathrm{H}) ;{ }^{13} \mathrm{C}$ NMR $(100 \mathrm{MHz}$, DMSO- $d_{6} /$ TFA- $d_{1}$ 2/1): $169.9(\mathrm{~s}), 167.2(\mathrm{~s}), 147.6$ (s), 147.4 (s), 129.2 (s), 128.7 (s), 126.4 (d), 126.3 (d), 124.6 (d), 124.4 (d), 109.4 (d), 108.3 (d), 66.4 (t), 64.9 (t).

1,4-Isomer 9. Yield: $88 \% ;{ }^{1} \mathrm{H}$ NMR (400 MHz, DMSO- $\left.d_{6} / \mathrm{TFA}-d_{1} 2 / 1\right): 8.31-8.29(\mathrm{~m}, 1 \mathrm{H})$, 8.22-8.19 (m, 1H), 7.53-7.51 (m, 2H), $6.76\left(\mathrm{~d},{ }^{3} J(\mathrm{H}, \mathrm{H})=8.4 \mathrm{~Hz}, 1 \mathrm{H}\right), 6.65\left(\mathrm{~d},{ }^{3} J(\mathrm{H}, \mathrm{H})=8.4\right.$ $\mathrm{Hz}, 1 \mathrm{H}), 4.58(\mathrm{~s}, 2 \mathrm{H}), 4.42(\mathrm{~s}, 2 \mathrm{H}) ;{ }^{13} \mathrm{C}$ NMR (100 MHz, DMSO-d $\left.d_{6} / \mathrm{TFA}-d_{1} 2 / 1\right): 171.7$ (s), 166.7 (s), 148.6 (s), 146.8 (s), 125.8 (s), 125.6 (s), 125.6 (d), 125.5 (d), 122.0 (d), 121.8 (d), $105.4(\mathrm{~d}), 104.4(\mathrm{~d}), 67.7(\mathrm{t}), 67.0(\mathrm{t})$.

1,3-Isomer 10. Yield: quant.; ${ }^{1} \mathrm{H}$ NMR $\left(400 \mathrm{MHz}, \mathrm{DMSO}-d_{6} / \mathrm{TFA}-d_{1} 2 / 1\right): 8.17\left(\mathrm{~d},{ }^{3} J(\mathrm{H}, \mathrm{H})\right.$ $=8.4 \mathrm{~Hz}, 1 \mathrm{H}), 7.65\left(\mathrm{~d},{ }^{3} J(\mathrm{H}, \mathrm{H})=8.4 \mathrm{~Hz}, 1 \mathrm{H}\right), 7.41\left(\mathrm{t},{ }^{3} J(\mathrm{H}, \mathrm{H})=8.4 \mathrm{~Hz}, 1 \mathrm{H}\right), 7.28\left(\mathrm{t},{ }^{3} J\right.$ $(\mathrm{H}, \mathrm{H})=8.4 \mathrm{~Hz}, 1 \mathrm{H}), 6.74(\mathrm{~s}, 1 \mathrm{H}), 6.58(\mathrm{~s}, 1 \mathrm{H}), 4.67(\mathrm{~s}, 2 \mathrm{H}), 4.34(\mathrm{~s}, 2 \mathrm{H}) ;{ }^{13} \mathrm{C}$ NMR $(100$ MHz, DMSO- $d_{6} /$ TFA- $d_{1}$ 2/1): $170.1(\mathrm{~s}), 166.5$ (s), 157.0 (s), 154.2 (s), 134.8 (s), 126.9 (d), $126.3(\mathrm{~d}), 122.5(\mathrm{~d}), 122.0(\mathrm{~d}), 120.5(\mathrm{~s}), 99.5(\mathrm{~d}), 99.4(\mathrm{~d}), 67.5(\mathrm{t}), 66.6(\mathrm{t})$.

1,6-Isomer 11. Yield: $86 \% ;{ }^{1} \mathrm{H}$ NMR $\left(400 \mathrm{MHz}, \mathrm{DMSO}-d_{6} / \mathrm{TFA}-d_{1} 2 / 1\right): 8.23\left(\mathrm{~d},{ }^{3} J(\mathrm{H}, \mathrm{H})=\right.$ $9.2 \mathrm{~Hz}, 1 \mathrm{H}), 7.29\left(\mathrm{dd},{ }^{3} J(\mathrm{H}, \mathrm{H})=8.0 \mathrm{~Hz},{ }^{3} J(\mathrm{H}, \mathrm{H})=1.6 \mathrm{~Hz}, 1 \mathrm{H}\right), 7.27\left(\mathrm{t},{ }^{3} J(\mathrm{H}, \mathrm{H})=8.0 \mathrm{~Hz}\right.$, $1 \mathrm{H}), 7.11\left(\mathrm{dd},{ }^{3} J(\mathrm{H}, \mathrm{H})=9.2 \mathrm{~Hz},{ }^{3} J(\mathrm{H}, \mathrm{H})=2.4 \mathrm{~Hz}, 1 \mathrm{H}\right), 6.70\left(\mathrm{dd},{ }^{3} J(\mathrm{H}, \mathrm{H})=8.0 \mathrm{~Hz},{ }^{3} J\right.$ $(\mathrm{H}, \mathrm{H})=1.6 \mathrm{~Hz}, 1 \mathrm{H}), 4.64(\mathrm{~s}, 2 \mathrm{H}), 4.37(\mathrm{~s}, 2 \mathrm{H}) ;{ }^{13} \mathrm{C}$ NMR $\left(100 \mathrm{MHz}\right.$, DMSO-d $d_{6} / \mathrm{TFA}^{-} d_{1}$ 2/1): 
171.7 (s), 166.5 (s), 157.9 (s), 153.5 (s), 135.6 (s), 126.4 (d), 123.5 (d), 119.7 (d), 117.9 (d), $106.6(d), 103.1(d), 67.4(t), 66.6(t)$.

3,1-Isomer 12. Yield: $77 \%$; ${ }^{1} \mathrm{H}$ NMR $\left(400 \mathrm{MHz}\right.$, DMSO- $\left.d_{6} / \mathrm{TFA}-d_{1} 2 / 1\right): 8.09\left(\mathrm{~d},{ }^{3} J(\mathrm{H}, \mathrm{H})=\right.$ $8.0 \mathrm{~Hz}, 1 \mathrm{H}), 7.70\left(\mathrm{~d},{ }^{3} J(\mathrm{H}, \mathrm{H})=8.0 \mathrm{~Hz}, 1 \mathrm{H}\right), 7.46\left(\mathrm{t},{ }^{3} J(\mathrm{H}, \mathrm{H})=8.0 \mathrm{~Hz}, 1 \mathrm{H}\right), 7.33\left(\mathrm{~d},{ }^{3} J(\mathrm{H}, \mathrm{H})\right.$ $=8.0 \mathrm{~Hz}, 1 \mathrm{H}), 6.82(\mathrm{~s}, 1 \mathrm{H}), 6.58(\mathrm{~s}, 1 \mathrm{H}), 4.58(\mathrm{~s}, 2 \mathrm{H}), 4.55(\mathrm{~s}, 2 \mathrm{H}) ;{ }^{13} \mathrm{C}$ NMR $(100 \mathrm{MHz}$, DMSO- $d_{6} /$ TFA- $d_{1}$ 2/1): $170.2(\mathrm{~s}), 166.5(\mathrm{~s}), 156.2(\mathrm{~s}), 155.2(\mathrm{~s}), 134.5$ (s), 126.9 (d), 126.5 (d), 122.9 (d), 121.9 (d), $121.3(\mathrm{~s}), 98.8$ (d), 98.8 (d), 67.5 (t), $66.3(\mathrm{t})$.

2,6-Isomer 13. Yield: $78 \%$; ${ }^{1} \mathrm{H}$ NMR $\left(400 \mathrm{MHz}, \mathrm{DMSO}-d_{6} / \mathrm{TFA}-d_{1} 2 / 1\right): 7.76\left(\mathrm{dd},{ }^{3} J(\mathrm{H}, \mathrm{H})\right.$ $\left.=6.0 \mathrm{~Hz},{ }^{3} \mathrm{~J}(\mathrm{H}, \mathrm{H})=2.8 \mathrm{~Hz}, 1 \mathrm{H}\right), 7.72\left(\mathrm{~d},{ }^{3} \mathrm{~J}(\mathrm{H}, \mathrm{H})=8.8 \mathrm{~Hz}, 1 \mathrm{H}\right), 7.31-7.18(\mathrm{~m}, 4 \mathrm{H}), 4.83(\mathrm{~s}$, 2H), 4.77 (s, 2H); ${ }^{13} \mathrm{C}$ NMR (100 MHz, DMSO- $\left.d_{6} / \mathrm{TFA}-d_{1} 2 / 1\right): 170.1$ (s), 167.2 (s), 154.4 (s), 153.9 (s), 129.5 (s), 129.3 (s), 128.4 (d), 128.3 (d), 119.0 (d), 118.8 (d), 107.5 (d), 107.2 $(\mathrm{d}), 65.8(\mathrm{t}), 64.5(\mathrm{t})$.<smiles>Oc1cccc2ccccc12</smiles>

24

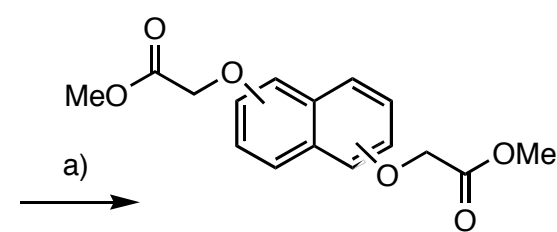

28

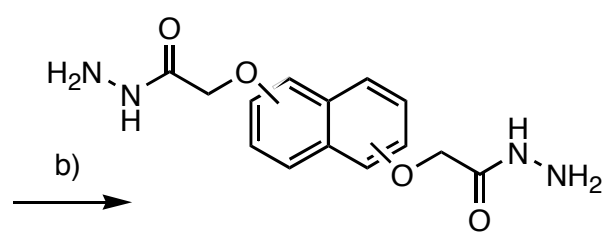

14-16

Scheme S2. a) Methyl bromoacetate, $\mathrm{K}_{2} \mathrm{CO}_{3}$, acetone; b) $\mathrm{H}_{2} \mathrm{NNH}_{2} \bullet \mathrm{H}_{2} \mathrm{O}, \mathrm{MeOH}$.

Isomers $\mathbf{2 8}$ (see Table 1 for isomers):

2,7-Isomer. A solution of the 2,7-isomer of $\mathbf{2 4}(1.0 \mathrm{~g}, 6.2 \mathrm{mmol})$, potassium carbonate $(2.2 \mathrm{~g}$, $15.6 \mathrm{mmol})$ and methyl bromoacetate $(2.3 \mathrm{~g}, 15.0 \mathrm{mmol})$ in acetone $(15 \mathrm{ml})$ was heated to 70 ${ }^{\circ} \mathrm{C}$ and stirred overnight. After cooling, the mixture was filtrated and poured into $0.1 \mathrm{~N} \mathrm{HCl}$, extracted with EtOAc, washed with water (2 times) and brine, dried with anhydrous $\mathrm{Na}_{2} \mathrm{SO}_{4}$, filtered and concentrated to obtain the 2,7-isomer of $\mathbf{2 8}(1.8 \mathrm{~g}, 92 \%)$ as a light brown powder. ${ }^{1} \mathrm{H}$ NMR $\left(400 \mathrm{MHz}, \mathrm{CDCl}_{3}\right): 7.75\left(\mathrm{~d},{ }^{3} J(\mathrm{H}, \mathrm{H})=8.8 \mathrm{~Hz}, 2 \mathrm{H}\right), 7.16\left(\mathrm{dd},{ }^{3} J(\mathrm{H}, \mathrm{H})=8.4 \mathrm{~Hz},{ }^{3} J\right.$ $(\mathrm{H}, \mathrm{H})=2.4 \mathrm{~Hz}, 2 \mathrm{H}), 7.03\left(\mathrm{~d},{ }^{3} J(\mathrm{H}, \mathrm{H})=2.4 \mathrm{~Hz}, 2 \mathrm{H}\right), 4.80(\mathrm{~s}, 4 \mathrm{H}), 3.89(\mathrm{~s}, 6 \mathrm{H}), 1.48(\mathrm{~s}, 9 \mathrm{H})$; ${ }^{13} \mathrm{C} \mathrm{NMR}\left(100 \mathrm{MHz}, \mathrm{CDCl}_{3}\right.$ ): 169.6 (s), 156.6 (s), 135.5 (s), 129.8 (d), 125.5 (s), 116.7 (d), $106.8(\mathrm{~d}), 65.5(\mathrm{t}), 52.6(\mathrm{q})$; ESI MS (MeOH/ $\mathrm{CH}_{2} \mathrm{Cl}_{2}$ 1:1): $305\left(100,[\mathrm{M}+\mathrm{H}]^{+}\right)$.

2,6-Isomer. A solution of the 2,6-isomer of $24(1.0 \mathrm{~g}, 6.2 \mathrm{mmol})$, potassium carbonate $(2.2 \mathrm{~g}$, $15.6 \mathrm{mmol})$ and methyl bromoacetate $(2.3 \mathrm{~g}, 15.0 \mathrm{mmol})$ in acetone $(15 \mathrm{ml})$ was heated to 70 ${ }^{\circ} \mathrm{C}$ and stirred overnight. After cooling, the mixture was filtrated and poured into $0.1 \mathrm{~N} \mathrm{HCl}$, extracted with EtOAc, washed with water (2 times) and brine, dried with anhydrous $\mathrm{Na}_{2} \mathrm{SO}_{4}$, filtered and concentrated to obtain the 2,6-isomer of $\mathbf{2 8}(1.0 \mathrm{~g}, 67 \%)$ as a light brown powder. ${ }^{1} \mathrm{H}$ NMR $\left(400 \mathrm{MHz}, \mathrm{CDCl}_{3}\right): 7.71\left(\mathrm{~d},{ }^{3} J(\mathrm{H}, \mathrm{H})=9.2 \mathrm{~Hz}, 2 \mathrm{H}\right), 7.27\left(\mathrm{dd},{ }^{3} J(\mathrm{H}, \mathrm{H})=8.4 \mathrm{~Hz},{ }^{3} J\right.$ $(\mathrm{H}, \mathrm{H})=2.0 \mathrm{~Hz}, 2 \mathrm{H}), 7.10\left(\mathrm{~d},{ }^{3} J(\mathrm{H}, \mathrm{H})=2.0 \mathrm{~Hz}, 2 \mathrm{H}\right), 4.79(\mathrm{~s}, 4 \mathrm{H}), 3.88(\mathrm{~s}, 6 \mathrm{H}), 1.48(\mathrm{~s}, 9 \mathrm{H})$; ${ }^{13} \mathrm{C} \mathrm{NMR}\left(100 \mathrm{MHz}, \mathrm{CDCl}_{3}\right.$ ): 169.6 (s), 154.8 (s), 130.2 (s), 128.9 (d), 119.3 (d), 107.6 (d), $82.5(\mathrm{~s}), 65.7$ (t), $52.6(\mathrm{q})$; ESI MS (MeOH/ $\mathrm{CH}_{2} \mathrm{Cl}_{2}$ 1:1): $305\left(100,[\mathrm{M}+\mathrm{H}]^{+}\right)$. 
2,7-Isomer 14. To a solution of the 2,7-isomer of $28(500 \mathrm{mg}, 1.6 \mathrm{mmol})$ in $\mathrm{MeOH}(15 \mathrm{ml})$, hydrazine monohydrate $(1 \mathrm{ml})$ was added at rt. The mixture was heated to $70{ }^{\circ} \mathrm{C}$ and stirred overnight. After cooling, the precipitate was triturated with $\mathrm{MeOH}$, filtered and washed with $\mathrm{MeOH}$ to give 14 (492 mg, 98\%) as a colorless solid. ${ }^{1} \mathrm{H}$ NMR (400 MHz, DMSO- $d_{6} / \mathrm{TFA}-d_{1}$ 2/1): $9.41(\mathrm{br}, 1 \mathrm{H}), 7.72\left(\mathrm{~d},{ }^{3} J(\mathrm{H}, \mathrm{H})=9.1 \mathrm{~Hz}, 2 \mathrm{H}\right), 7.26(\mathrm{~s}, 2 \mathrm{H}), 7.23\left(\mathrm{~d},{ }^{3} J(\mathrm{H}, \mathrm{H})=9.1 \mathrm{~Hz}\right.$, 2H), 4.57 (s, 4H); ${ }^{13} \mathrm{C}$ NMR (100 MHz, DMSO- $\left.d_{6} / \mathrm{TFA}-d_{1} 2 / 1\right): 167.4$ (s), 154.0 (s), 129.5 (s), 128.4 (d), 118.9 (d), 107.6 (d), 65.6 (t); ESI MS (MeOH/DMSO/TFA 10:10:1): 305 (100, $\left.[\mathrm{M}+\mathrm{H}]^{+}\right)$.

1,5-Isomer 15. This compound was prepared following previously reported procedures. ${ }^{\mathrm{S} 1}$

2,6-Isomer 16. To a solution of 2,6-isomer of $28(500 \mathrm{mg}, 1.6 \mathrm{mmol})$ in $\mathrm{MeOH}(15 \mathrm{ml})$, hydrazine monohydrate $(1 \mathrm{ml})$ was added at rt. The mixture was heated to $70{ }^{\circ} \mathrm{C}$ and stirred overnight. After cooling, the precipitate was subjected to solid/liquid extraction with $\mathrm{MeOH}$, filtered and washed with $\mathrm{MeOH}$ to give $\mathbf{1 6}(491 \mathrm{mg}, 98 \%)$ as a colorless solid. ${ }^{1} \mathrm{H}$ NMR (400 MHz, DMSO- $d_{6} /$ TFA- $d_{1}$ 2/1): $9.42(\mathrm{br}, 1 \mathrm{H}), 7.76\left(\mathrm{~d},{ }^{3} J(\mathrm{H}, \mathrm{H})=8.8 \mathrm{~Hz}, 2 \mathrm{H}\right), 7.16(\mathrm{~s}, 2 \mathrm{H})$, $7.09\left(\mathrm{~d},{ }^{3} \mathrm{~J}(\mathrm{H}, \mathrm{H})=8.8 \mathrm{~Hz}, 2 \mathrm{H}\right), 4.59(\mathrm{~s}, 4 \mathrm{H}) ;{ }^{13} \mathrm{C}$ NMR $\left(100 \mathrm{MHz}, \mathrm{DMSO}-d_{6} / \mathrm{TFA}-d_{1} 2 / 1\right)$ : 167.3 (s), 155.9 (s), 135.1 (s), 129.3 (d), 124.7 (s), 116.2 (d), 106.8 (d), 65.6 (t); ESI MS (MeOH/DMSO/TFA 10:10:1): $305\left(100,[\mathrm{M}+\mathrm{H}]^{+}\right)$.

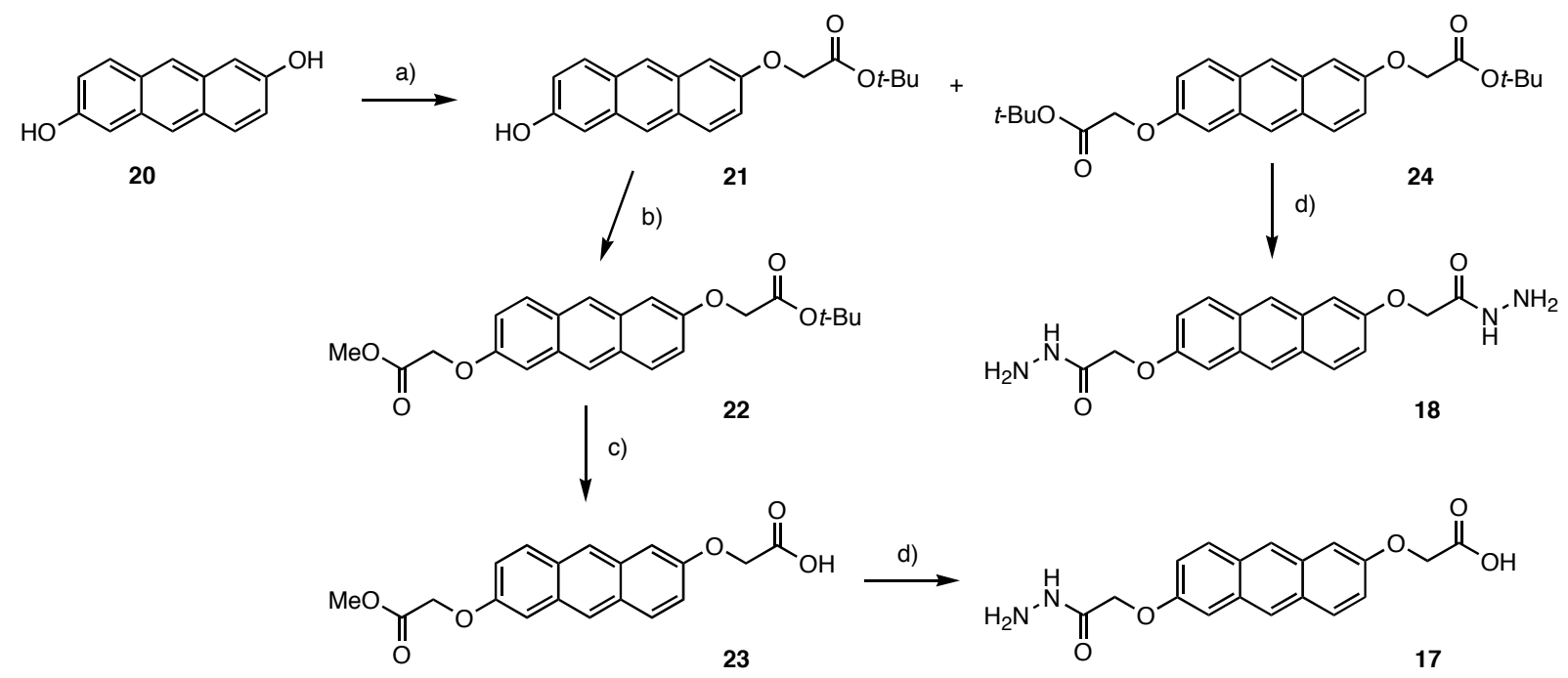

Scheme S3. a) $t$-Butyl bromoacetate, $\mathrm{K}_{2} \mathrm{CO}_{3}$, acetone; b) methyl bromoacetate, $\mathrm{K}_{2} \mathrm{CO}_{3}$, acetone; c) TFA, $\mathrm{CH}_{2} \mathrm{Cl}_{2}$; d) $\mathrm{H}_{2} \mathrm{NNH}_{2} \bullet \mathrm{H}_{2} \mathrm{O}, \mathrm{MeOH}$.

2,7-Dihydroxyanthracene 20. This compound was prepared from anthraquinone 19 in 4 steps following previously reported procedures. ${ }^{\mathrm{S} 2}$

2-Alkoxy-7-hydroxyanthracene 21 and 2,7-Dialkoxyanthracene 24. A solution of 20 (2.0 $\mathrm{g}, 9.5 \mathrm{mmol})$, potassium carbonate $(1.8 \mathrm{~g}, 13.3 \mathrm{mmol})$ and $t$-butyl bromoacetate $(2.0 \mathrm{ml}, 13.3$ mmol) in acetone $(20 \mathrm{ml})$ was heated to $70{ }^{\circ} \mathrm{C}$ and stirred overnight. After cooling, the mixture was poured into $1 \mathrm{~N} \mathrm{HCl}(50 \mathrm{ml})$, extracted with $\mathrm{CH}_{2} \mathrm{Cl}_{2}$, washed with water (2 times) and brine, dried with anhydrous $\mathrm{Na}_{2} \mathrm{SO}_{4}$, filtered and concentrated. Purification of the crude product by column chromatography $\left(\mathrm{CH}_{2} \mathrm{Cl}_{2}\right)$ yielded pure $21(473 \mathrm{mg}, 16 \%)$ and $24(607 \mathrm{mg}$, $15 \%)$ as colorless solids. 21. ${ }^{1} \mathrm{H}$ NMR $\left(400 \mathrm{MHz}, \mathrm{CDCl}_{3}\right): 8.23(\mathrm{~s}, 1 \mathrm{H}), 8.20(\mathrm{~s}, 1 \mathrm{H}), 7.93$ 
$\left(\mathrm{d},{ }^{3} J(\mathrm{H}, \mathrm{H})=9.2 \mathrm{~Hz}, 1 \mathrm{H}\right), 7.90\left(\mathrm{~d},{ }^{3} J(\mathrm{H}, \mathrm{H})=9.2 \mathrm{~Hz}, 1 \mathrm{H}\right), 7.30\left(\mathrm{~d},{ }^{3} J(\mathrm{H}, \mathrm{H})=9.2 \mathrm{~Hz}, 1 \mathrm{H}\right)$, $7.27(\mathrm{~s}, 1 \mathrm{H}), 7.19\left(\mathrm{~d},{ }^{3} J(\mathrm{H}, \mathrm{H})=9.2 \mathrm{~Hz}, 1 \mathrm{H}\right), 7.13(\mathrm{~s}, 1 \mathrm{H}), 4.72(\mathrm{~s}, 2 \mathrm{H}), 1.57(\mathrm{~s}, 9 \mathrm{H}) ;{ }^{13} \mathrm{C}$ NMR (100 MHz, DMSO- $d_{6}$ ): 169.6 (s), 168.2 (s), 154.1 (s), 154.0 (s), 131.5 (s), 129.9 (s), 129.2 (d), 129.2 (d), 128.3 (s), 127.7 (s), 124.2 (d), 123.1 (d), 120.6 (d), 120.0 (d), 106.7 (d), 105.2 (d), 81.4 (s), 65.0 (t), 27.7 (q); ESI MS (MeOH/CH $\mathrm{Cl}_{2}$ 1:1): $324\left(30,[\mathrm{M}+\mathrm{H}]^{+}\right), 269$ $\left(100,[\mathrm{M}-t-\mathrm{Bu}+\mathrm{H}]^{+}\right)$. 24. ${ }^{1} \mathrm{H}$ NMR $\left(400 \mathrm{MHz}, \mathrm{CDCl}_{3}\right): 8.23(\mathrm{~s}, 2 \mathrm{H}), 7.92\left(\mathrm{~d},{ }^{3} J(\mathrm{H}, \mathrm{H})=\right.$ $9.2 \mathrm{~Hz}, 2 \mathrm{H}), 7.30\left(\mathrm{~d},{ }^{3} \mathrm{~J}(\mathrm{H}, \mathrm{H})=9.2 \mathrm{~Hz}, 2 \mathrm{H}\right), 7.15(\mathrm{~s}, 2 \mathrm{H}), 4.72(\mathrm{~s}, 4 \mathrm{H}), 1.57(\mathrm{~s}, 18 \mathrm{H}) ;{ }^{13} \mathrm{C}$ NMR (100 MHz, $\mathrm{CDCl}_{3}$ ): 168.2 (s), 155.1 (s), 131.3 (s), 129.8 (d), 129.1 (s), 124.7 (d), 120.7 (d), 105.4 (d), 82.7 (s), 65.9 (t), 28.3 (q); ESI MS (MeOH/ $\mathrm{CH}_{2} \mathrm{Cl}_{2}$ 1:1): $456\left(70,\left[\mathrm{M}+\mathrm{NH}_{4}\right]^{+}\right)$, $439\left(90,[\mathrm{M}+\mathrm{H}]^{+}\right), 383\left(95,[\mathrm{M}-t-\mathrm{Bu}+\mathrm{H}]^{+}\right), 327\left(100,[\mathrm{M}-t-\mathrm{Bu} 2+\mathrm{H}]^{+}\right)$.

2,7-DAA 22. A solution of 21 (400 $\mathrm{mg}, 1.2 \mathrm{mmol})$, potassium carbonate ( $250 \mathrm{mg}, 1.8 \mathrm{mmol})$ and methyl bromoacetate $(166 \mu \mathrm{l}, 1.8 \mathrm{mmol})$ in acetone $(10 \mathrm{ml})$ was heated to $70{ }^{\circ} \mathrm{C}$ and stirred overnight. After cooling, the mixture was filtrated and poured into $0.1 \mathrm{~N} \mathrm{HCl}$, extracted with $\mathrm{CH}_{2} \mathrm{Cl}_{2}$, washed with water (2 times) and brine, dried with anhydrous $\mathrm{Na}_{2} \mathrm{SO}_{4}$, filtered and concentrated. Purification of the crude product by column chromatography $\left(\mathrm{CH}_{2} \mathrm{Cl}_{2}\right)$ yielded $22(390 \mathrm{mg}, 82 \%)$ as a colorless solid. ${ }^{1} \mathrm{H} \mathrm{NMR}\left(400 \mathrm{MHz}, \mathrm{CDCl}_{3}\right): 8.26$ $(\mathrm{s}, 1 \mathrm{H}), 8.24(\mathrm{~s}, 1 \mathrm{H}), 7.94\left(\mathrm{~d},{ }^{3} J(\mathrm{H}, \mathrm{H})=9.2 \mathrm{~Hz}, 1 \mathrm{H}\right), 7.93\left(\mathrm{~d},{ }^{3} J(\mathrm{H}, \mathrm{H})=9.2 \mathrm{~Hz}, 1 \mathrm{H}\right), 7.30(\mathrm{~d}$, $\left.{ }^{3} J(\mathrm{H}, \mathrm{H})=9.2 \mathrm{~Hz},{ }^{2} \mathrm{H}\right), 7.16(\mathrm{~s}, 1 \mathrm{H}), 7.15(\mathrm{~s}, 1 \mathrm{H}), 4.85(\mathrm{~s}, 2 \mathrm{H}), 4.72(\mathrm{~s}, 2 \mathrm{H}), 3.91(\mathrm{~s}, 3 \mathrm{H}), 1.57$ (s, 9H); ${ }^{13} \mathrm{C}$ NMR (100 MHz, $\mathrm{CDCl}_{3}$ ): 169.5 (s), 168.1 (s), 155.2 (s), 154.7 (s), 131.4 (s), 131.2 (s), 129.9 (d), 129.8 (d), 129.2 (s), 129.2 (s), 124.8 (d), 124.7 (d), 120.7 (d), 120.5, (d), 105.3 (d), 105.3 (d), 82.7 (s), 65.9 (t), 65.5 (t), 52.6 (q), 28.3 (q); ESI MS (MeOH/CH $\mathrm{Cl}_{2}$ 1:1): $397\left(90,[\mathrm{M}+\mathrm{H}]^{+}\right), 341\left(100,[\mathrm{M}-t-\mathrm{Bu}+\mathrm{H}]^{+}\right)$.

2,7-DAA 23. To a solution of $22(350 \mathrm{mg}, 0.9 \mathrm{mmol})$ in $\mathrm{CH}_{2} \mathrm{Cl}_{2}(10 \mathrm{ml})$, TFA ( $\left.3 \mathrm{ml}\right)$ was added at rt. After stirring $2 \mathrm{hrs}$ at rt, the solvent was evaporated to yield $\mathbf{2 3}$ (306 $\mathrm{mg}$, quant) as a colorless solid. ${ }^{1} \mathrm{H}$ NMR $\left(400 \mathrm{MHz}, \mathrm{DMSO}-d_{6}\right): 8.35(\mathrm{~s}, 2 \mathrm{H}), 7.97\left(\mathrm{~d},{ }^{3} \mathrm{~J}(\mathrm{H}, \mathrm{H})=9.2 \mathrm{~Hz}\right.$, 2H), $7.32(\mathrm{~s}, 1 \mathrm{H}), 7.30(\mathrm{~s}, 1 \mathrm{H}), 7.26-7.23(\mathrm{~m}, 2 \mathrm{H}), 4.96(\mathrm{~s}, 2 \mathrm{H}), 4.84(\mathrm{~s}, 2 \mathrm{H}), 3.76(\mathrm{~s}, 3 \mathrm{H}) ;{ }^{13} \mathrm{C}$ NMR (100 MHz, DMSO- $\left.d_{6}\right)$ : 170.1 (s), 169.1 (s), 154.6 (s), 154.4 (s), 130.8 (s), 130.6 (s), 129.5 (d), 129.4 (d), 128.4 (s), 128.3 (s), 124.4 (d), 124.3 (d), 120.3 (d), 120.2 (d), 105.3 (d), 105.1 (d), 64.6 (t), 64.5 (t), 51.9 (q); ESI MS (MeOH/ $\mathrm{CH}_{2} \mathrm{Cl}_{2}$ 1:1): $341\left(100,[\mathrm{M}+\mathrm{H}]^{+}\right)$.

2,7-DAA 17. To a solution of $23(280 \mathrm{mg}, 0.82 \mathrm{mmol})$ in $\mathrm{MeOH}(10 \mathrm{ml})$, hydrazine monohydrate $(2 \mathrm{ml})$ was added at $\mathrm{rt}$. The mixture was heated to $70{ }^{\circ} \mathrm{C}$ and stirred overnight. After cooling, the precipitate was subjected to solid/liquid extraction with $\mathrm{MeOH}$, filtered and washed with $\mathrm{MeOH}$ to give 17 (280 mg, quant) as a colorless solid. ${ }^{1} \mathrm{H}$ NMR (400 MHz, DMSO- $d_{6} /$ TFA- $\left.d_{1} 2 / 1\right): 8.37(\mathrm{~s}, 1 \mathrm{H}), 8.33(\mathrm{~s}, 1 \mathrm{H}), 8.10\left(\mathrm{~d},{ }^{3} J(\mathrm{H}, \mathrm{H})=9.2 \mathrm{~Hz}, 1 \mathrm{H}\right), 7.99\left(\mathrm{~d},{ }^{3} J\right.$ $(\mathrm{H}, \mathrm{H})=9.2 \mathrm{~Hz}, 1 \mathrm{H}), 7.35(\mathrm{~s}, 1 \mathrm{H}), 7.30(\mathrm{~s}, 1 \mathrm{H}), 7.28\left(\mathrm{~d},{ }^{3} J(\mathrm{H}, \mathrm{H})=9.2 \mathrm{~Hz}, 1 \mathrm{H}\right), 7.25\left(\mathrm{~d},{ }^{3} J\right.$ $(\mathrm{H}, \mathrm{H})=9.2 \mathrm{~Hz}, 1 \mathrm{H}), 4.93(\mathrm{~s}, 2 \mathrm{H}), 4.85(\mathrm{~s}, 2 \mathrm{H}) ;{ }^{13} \mathrm{C}$ NMR $\left(100 \mathrm{MHz}, \mathrm{DMSO}-d_{6} / \mathrm{TFA}_{-} d_{1}\right.$ 2/1): 170.0 (s), 167.3 (s), 154.6 (s), 154.2 (s), 130.9 (s), 130.5 (s), 129.5 (d), 129.4 (d), 128.4 (s), 128.4 (s), 124.4 (d), 124.4 (d), 120.4 (d), 120.1 (d), 105.5 (d), 105.0 (d), 65.6 (t), 64.4 (t); ESI MS (MeOH/CH $\mathrm{Cl}_{2}$ 1:1): $358\left(100,\left[\mathrm{M}+\mathrm{NH}_{4}\right]^{+}\right), 341\left(50,[\mathrm{M}+\mathrm{H}]^{+}\right)$.

2,7-DAA 18. To a solution of $24(250 \mathrm{mg}, 0.57 \mathrm{mmol})$ in $\mathrm{MeOH}(10 \mathrm{ml})$, hydrazine monohydrate $(2 \mathrm{ml})$ was added at $\mathrm{rt}$. The mixture was heated to $70{ }^{\circ} \mathrm{C}$ and stirred overnight. After cooling, the precipitate was subjected to solid/liquid extraction with $\mathrm{MeOH}$, filtered and washed with $\mathrm{MeOH}$ to give $18(200 \mathrm{mg}, 98 \%)$ as a colorless solid. ${ }^{1} \mathrm{H}$ NMR (400 $\mathrm{MHz}$, DMSO- $d_{6} /$ TFA- $\left.d_{1} 2 / 1\right): 8.36(\mathrm{~s}, 2 \mathrm{H}), 8.03\left(\mathrm{~d},{ }^{3} J(\mathrm{H}, \mathrm{H})=9.2 \mathrm{~Hz}, 2 \mathrm{H}\right), 7.37(\mathrm{~s}, 2 \mathrm{H}), 7.30\left(\mathrm{~d},{ }^{3} J\right.$ 
$(\mathrm{H}, \mathrm{H})=9.2 \mathrm{~Hz}, 2 \mathrm{H}), 4.93(\mathrm{~s}, 4 \mathrm{H}) ;{ }^{13} \mathrm{C}$ NMR (100 MHz, DMSO- $\left.d_{6} / \mathrm{TFA}-d_{1} 2 / 1\right): 167.3(\mathrm{~s})$, 154.3 (s), 130.7 (s), 129.4 (d), 128.5 (s), 124.4 (d), 120.2 (d), 105.4 (d), 65.5 (t); ESI MS $\left(\mathrm{MeOH} / \mathrm{CH}_{2} \mathrm{Cl}_{2}\right.$ 1:1): $355\left(100,[\mathrm{M}+\mathrm{H}]^{+}\right)$.

Hydrazone Formation (General Procedure). As in S1: A solution of hydrazide (10 $\mu \mathrm{mol})$ in 1.0 M pyruvic acid or $\alpha$-ketoglutaralic acid in DMSO (100 $\mu 1,100 \mathrm{mmol})$ was stirred for 2 hrs at $50{ }^{\circ} \mathrm{C}$. Then, $80 \mu \mathrm{l}$ of the mixture was diluted with buffer $(3.9 \mathrm{ml} ; \mathrm{pH} 6.5,107 \mathrm{mM}$ $\mathrm{NaCl}, 10 \mathrm{mM}$ HEPES) to afford the $2 \mathrm{mM}$ stock solution for pore blockage experiments.

EYPC-LUVs $\supset$ CF. As in ref (S1): Solutions of EYPC (25 mg) in $\mathrm{CHCl}_{3} / \mathrm{MeOH} 1 / 1(1 \mathrm{ml})$ were dried under vacuum $(>2 \mathrm{~h})$ to form thin films. The resulting films were hydrated with 1 $\mathrm{ml}$ buffer $(50 \mathrm{mM} \mathrm{CF}, 10 \mathrm{mM} \mathrm{NaCl}, 10 \mathrm{mM}$ HEPES, pH 7.4) for more than $30 \mathrm{~min}$, freezethawed $(5 x)$ and extruded (15x, Mini-Extruder with a stacked polycarbonate membrane, pore size $100 \mathrm{~nm}$ ). External CF was removed by gel filtration (Sephadex G-50) with buffer (107 $\mathrm{mM} \mathrm{NaCl}, 10 \mathrm{mM}$ HEPES, $\mathrm{pH}$ 7.4). The combined LUV fractions were diluted to $6 \mathrm{ml}$ with the corresponding buffer. Lipid concentrations were estimated from the amount of entrapped dye; the estimated values were in agreement with earlier results from phosphate analysis. The final stock solutions were as follows: $2.5 \mathrm{mM}$ EYPC; inside, $50 \mathrm{mM} \mathrm{CF}, 10 \mathrm{mM} \mathrm{NaCl}, 10$ mM HEPES, pH 7.4; outside, 107 mM NaCl, 10 mM HEPES, pH 7.4.

Pore Blockage. Analog to ref (S1): $100 \mu 1$ from above stock solutions of EYPC-LUVs $\supset C F$ were added to $1.90 \mathrm{ml}$ gently stirred, thermostated buffer in a fluorescence cuvette $(10 \mathrm{mM}$ HEPES, $107 \mathrm{mM} \mathrm{NaCl}, \mathrm{pH} 6.5)$. Fluorescence emission intensity $F_{\mathrm{t}}\left(\lambda_{\mathrm{ex}} 492 \mathrm{~nm}, \lambda_{\mathrm{em}} 517 \mathrm{~nm}\right)$ was monitored as a function of time during addition of blockers (from concentrated stock solutions in DMSO (above) or buffer, final concentrations 0.01-3000 $\mu \mathrm{M}$, compare Figure 2 and Table 1), pore 1 (20 $\mu \mathrm{l}$ of $37.5 \mu \mathrm{M}$ DMSO stock solution, final concentration, $375 \mathrm{nM}$ monomer 1m, < $94 \mathrm{nM}$ tetramer 1) and $40 \mu \mathrm{l} 1.2 \%$ aq triton $\mathrm{X}-100$ for final calibration. The fluorescence time courses were normalized to fractional emission

$$
I=\left(F_{\mathrm{t}}-F_{0}\right) /\left(F_{\infty}-F_{0}\right)
$$

where $F_{0}=F_{\mathrm{t}}$ at pore addition, $F_{\infty}=F_{\mathrm{t}}$ at saturation after lysis. The obtained $I$ was further converted into fractional pore activity

$$
Y=\left(I^{\mathrm{F}}-I_{\text {MIN }}^{\mathrm{F}}\right) /\left(I_{\text {MAX }}^{\mathrm{F}}-I^{\mathrm{F}}{ }_{\text {MN }}\right) \quad[\mathrm{S} 2],
$$

where $I^{\mathrm{F}}$ is $I$ before lysis, $I_{\text {MAX }}^{\mathrm{F}}$ is the maximal $I^{\mathrm{F}}$ and $I^{\mathrm{F}}{ }_{\text {MIN }}$ the minimal $I^{\mathrm{F}}$ of a dose response experiment. Fractional pore activities $Y$ were fitted to the Hill equation

$$
Y=Y_{\infty}+\left(Y_{0}-Y_{\infty}\right) /\left\{1+\left(c_{\text {BLOCKER }} / I C_{50}\right)^{\mathrm{n}}\right\} \quad[\mathrm{S} 3] \text {, }
$$

where $Y_{0}$ is $Y$ without ligand, $Y_{\infty}$ is $Y$ with excess ligand, $I C_{50}$ the concentration for $50 \%$ inhibition and $n$ the Hill coefficient.

Oxidation Potentials. Voltammograms were measured in $0.1 \mathrm{M}$ tetrabutylammonium hexafluorophosphate acetonitrile containing $10 \mathrm{mM}$ sample. A Pt working electrode with a diameter of $2 \mathrm{~mm}$ was used. The counter electrode was a Pt wire. $\mathrm{An} \mathrm{Ag} \mid \mathrm{Ag}^{+}$electrode (0.01 $\mathrm{M} \mathrm{AgNO}_{3}$ in acetonitrile) was used as reference electrode. Ferrocene (Fc) was added in some 
experiments to use the $\mathrm{Fc} / \mathrm{Fc}^{+}$couple as the reference. The electrolytic cell consisted of a single compartment cell equipped with the working, counter and reference electrodes. Results are summarized in Table 1 (methoxy isomers) and S1 (methoxy isomers compared to literature values).

Table S1. The half-wave oxidation potentials, $\mathrm{E}_{\mathrm{M}} \mathrm{OX}^{\mathrm{X}}$, of dimethoxyanthracene and dimethoxy naphthalenes in acetnitrile

\begin{tabular}{|c|c|c|c|c|}
\hline \multirow{2}{*}{ Compound } & & \multicolumn{3}{|c|}{$\mathrm{E}_{\mathrm{M}} \mathrm{OX} / \mathrm{V}$ vs. $\mathrm{Fc} / \mathrm{Fc}^{+}$} \\
\hline & & present study ${ }^{a}$ & $\operatorname{Ref} S 3^{b}$ & Ref $S 4^{b}$ \\
\hline & $17 c$ & 0.68 & - & - \\
\hline & $9 c$ & 0.72 & 0.65 & - \\
\hline & $13 c$ & 0.84 & 0.88 & 0.69 \\
\hline & $6 c / 7 c$ & 0.79 & 0.83 & - \\
\hline & $10 c / 12 c$ & - & 0.81 & - \\
\hline & $5 c$ & 1.02 & 1.02 & 0.89 \\
\hline & $8 c$ & 1.12 & 0.94 & - \\
\hline
\end{tabular}

${ }^{\mathrm{a} O x i d a t i o n ~ p o t e n t i a l s ~ d e t e r m i n e d ~ b y ~ c y c l i c ~ v o l t a m m e t r y ~ i n ~ a c e t n i t r i l e ~ a g a i n s t ~} \mathrm{Fc} / \mathrm{Fc}^{+}$. ${ }^{\mathrm{b}}$ Potential in literature was converted to the value against $\mathrm{Fc} / \mathrm{Fc}^{+}$considering that $0 \mathrm{~V}$ vs. $\mathrm{SCE}=-0.45 \mathrm{~V}$ vs. $\mathrm{Fc} / \mathrm{Fc}^{+}$. 

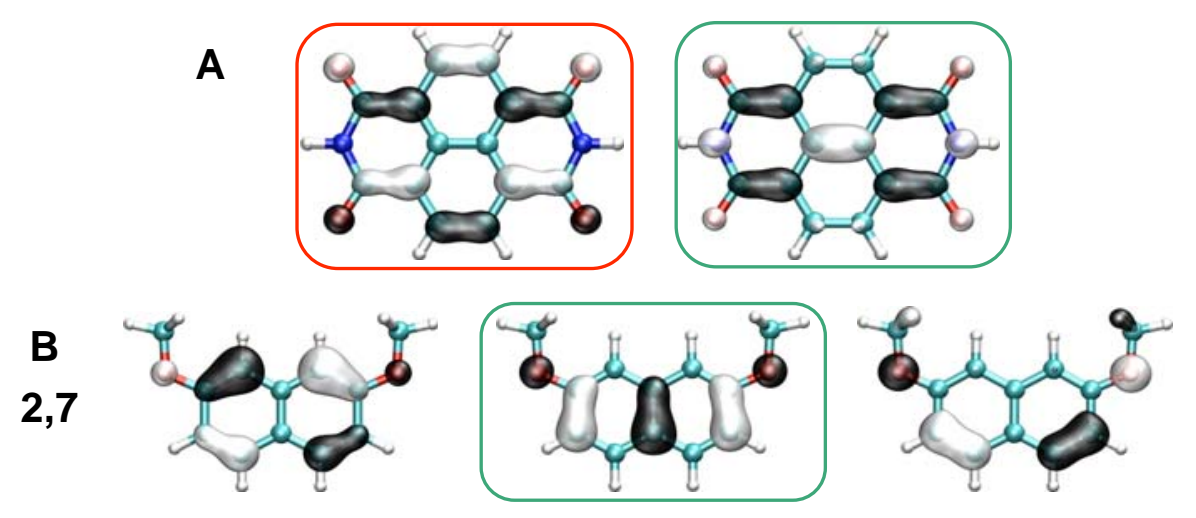

2,3
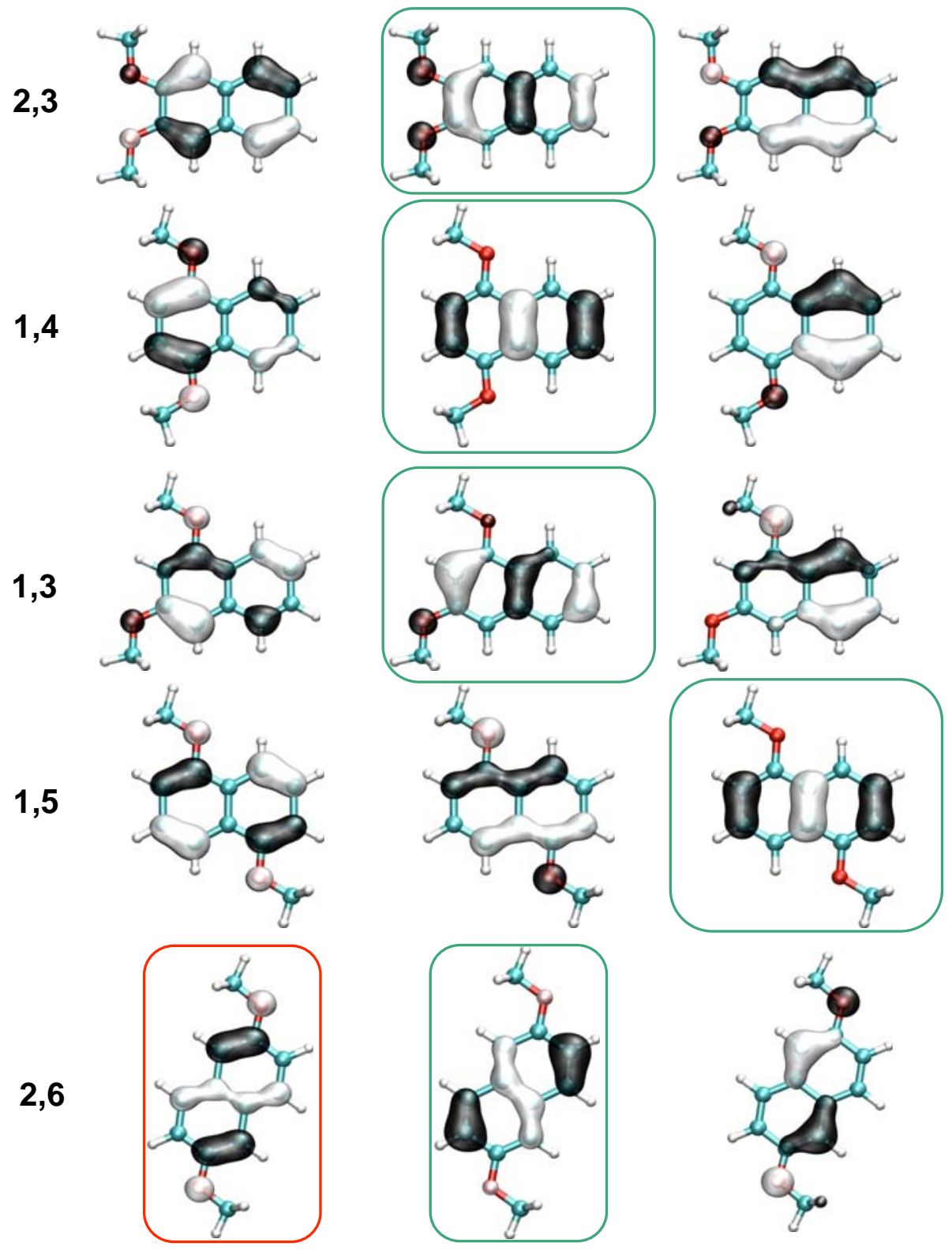
Fig. S1. (A) The two lowest unoccupied orbitals (LUMOs) of NDIs. (B) The three highest occupied orbitals (HOMOs) of dimethoxylnaphtalene isomers 2,7 (5c), 2,3 (8c), 1,4 (9c), 1,3 $(\mathbf{1 0 c / 1 2 c})$ and 2,6 (13c). The best matching DAN HOMOs (color frame) are oriented for best fit with LUMOs of NDI in notional AEDA complexes.

2,6
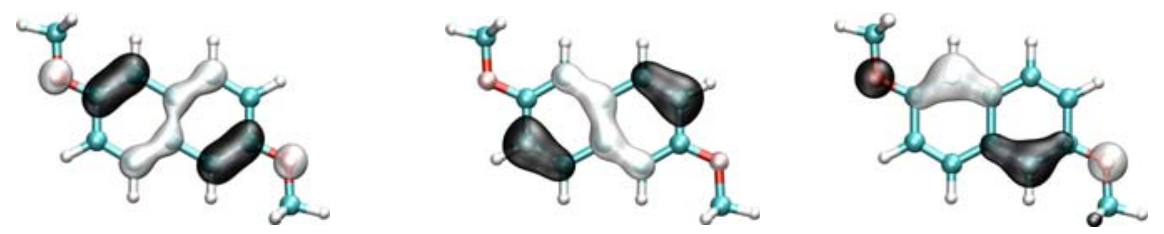

2,7
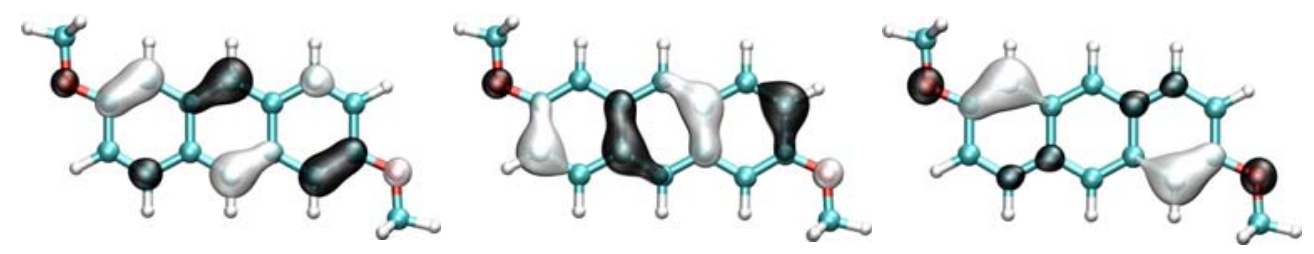

Fig. S2. Comparison of the HOMOs of DAN isomer 2,6 (13c) and DAA isomer 2,7 (17c).

Computational Methods. The geometry parameters and selected electronic properties of NDI, dimethoxynaphtalene regioisomers and 2,7-dimethoxyanthracene were investigated with the density functional (DFT) method. More specifically, the PBE1PBE functional ${ }^{\mathrm{S} 6}$ within Gaussion-03 package ${ }^{\mathrm{S} 7}$ was used as the main computational method throughout this study. This particular functional was shown to yield very good results for variety of organic substrates. ${ }^{\mathrm{S}, \mathrm{S} 9}$ The structure optimization and energy calculations were typically performed with the $6-311++\mathrm{G}^{* *}$ basis set while imposing an appropriate symmetry such as $\mathrm{C}_{\mathrm{s}}, \mathrm{C}_{2 \mathrm{v}}$, or $\mathrm{D}_{2 \mathrm{~h}}$. The nature of optimized minima and transition states was further checked by computations of analytical harmonic frequencies, to verify the absence of negative eigenvalues for minima. The global quadrupole moments $\mathrm{Q}_{\mathrm{zz}}$ in Buckinghams $(1 \mathrm{~B}=3.336 \mathrm{x}$ $10^{-40} \mathrm{C} \mathrm{m}^{2}$ ) perpendicular to the NDI plan were computed at MP2/6-311G** level $^{\mathrm{S} 10-\mathrm{S} 12}$ via a single point calculations based on PBE1PBE/6-311++G** optimized geometries (Table 1). The molecular orbitals are represented with VMD program. ${ }^{\mathrm{S} 13}$ 


\section{References}

S1. Tanaka, H.; Litvinchuk, S.; Bollot, G.; Mareda, J.; Tran, D.-H.; Sakai, N.; Matile, S. J. Am. Chem. Soc. 2006, 128, 16000-16001.

S2. Méry, S.; Haristoy, D.; Nicoud, J.F.; Guillon, D.; Monobe, H.; Shimizu, Y. J. Mater. Chem. 2003, 13, 1622-1630.

S3. Zweig, A.; Maurer, A. H.; Roberts, B. G. J. Org. Chem. 1967, 32, 1322-1329.

S4. Abdel-Shafi, A. A.; Wilkinson, F. Phys. Chem. Chem. Phys. 2002, 4, 248-254.

S5. Gorteau, V.; Bollot, G.; Mareda, J.; Matile, S. Org. Biomol. Chem. 2007, 5, 30003012.

S6. $\quad$ Perdew, J. P.; Burke, K.; Ernzerhof, M. Phys. Rev. Lett., 1996, 77, 3865-3868.

S7. Gaussian 03, Revision C.02, Frisch, M. J.; Trucks, G. W.; Schlegel, H. B.; Scuseria, G. E.; Robb, M. A.; Cheeseman, J. R.; Montgomery, Jr., J. A.; Vreven, T.; Kudin, K. N.; Burant, J. C.; Millam, J. M.; Iyengar, S. S.; Tomasi, J.; Barone, V.; Mennucci, B.; Cossi, M.; Scalmani, G.; Rega, N.; Petersson, G. A.; Nakatsuji, H.; Hada, M.; Ehara, M.; Toyota, K.; Fukuda, R.; Hasegawa, J.; Ishida, M.; Nakajima, T.; Honda, Y.; Kitao, O.; Nakai, H.; Klene, M.; Li, X.; Knox, J. E.; Hratchian, H. P.; Cross, J. B.; Bakken, V.; Adamo, C.; Jaramillo, J.; Gomperts, R.; Stratmann, R. E.; Yazyev, O.; Austin, A. J.; Cammi, R.; Pomelli, C.; Ochterski, J. W.; Ayala, P. Y.; Morokuma, K.; Voth, G. A.; Salvador, P.; Dannenberg, J. J.; Zakrzewski, V. G.; Dapprich, S.; Daniels, A. D.; Strain, M. C.; Farkas, O.; Malick, D. K.; Rabuck, A. D.; Raghavachari, K.; Foresman, J. B.; Ortiz, J. V.; Cui, Q.; Baboul, A. G.; Clifford, S.; Cioslowski, J.; Stefanov, B. B.; Liu, G.; Liashenko, A.; Piskorz, P.; Komaromi, I.; Martin, R. L.; Fox, D. J.; Keith, T.; Al-Laham, M. A.; Peng, C. Y.; Nanayakkara, A.; Challacombe, M.; Gill, P. M. W.; Johnson, B.; Chen, W.; Wong, M. W.; Gonzalez, C.; Pople, J. A.; Gaussian, Inc., Wallingford CT, 2004.

S8. Zhao, Y.; Truhlar, D. G. J. Phys. Chem. A 2004, 108, 6908-6918.

S9. Zhao, Y.; Truhlar, D. G. J. Chem. Theory Comput. 2005, 1, 415-432.

S10. Moller, C.; Plesset, M. S. Phys. Rev. 1934, 46, 618.

S11. Krishnan, R.; Pople, J. A. Int. J. Quantum Chem. 1978, 14, 91.

S12. Frisch, M. J.; Head-Gordon, M.; Pople, J. A. Chem. Phys. Lett. 1990, 166, 281.

S13. Humphrey, W.; Dalke, A.; Schulten, K. J. Molec. Graphics 1996, 14, 33-38. 